\title{
Abnormal Microglia and Enhanced Inflammation-Related Gene Transcription in Mice with Conditional Deletion of Ctcf in Camk2a-Cre-Expressing Neurons
}

\author{
Bryan E. McGill, ${ }^{1}$ Ruteja A. Barve, ${ }^{2}$ Susan E. Maloney, ${ }^{3}$ Amy Strickland, ${ }^{4}$ Nicholas Rensing, ${ }^{1}$ Peter L. Wang, ${ }^{4}$ \\ Michael Wong, ${ }^{1}$ - Richard Head, ${ }^{2}$ David F. Wozniak, ${ }^{3}$ and Jeffrey Milbrandt ${ }^{4}$ \\ ${ }^{1}$ Division of Pediatric and Developmental Neurology, Department of Neurology, ${ }^{2}$ Genome Technology Access Center, Department of Genetics, \\ ${ }^{3}$ Department of Psychiatry, and ${ }^{4}$ Department of Genetics, Washington University, St. Louis, Missouri 63110
}

CCCTC-binding factor (CTCF) is an 11 zinc finger DNA-binding domain protein that regulates gene expression by modifying 3D chromatin structure. Human mutations in CTCF cause intellectual disability and autistic features. Knocking out Ctcf in mouse embryonic neurons is lethal by neonatal age, but the effects of CTCF deficiency in postnatal neurons are less well studied. We knocked out Ctcf postnatally in glutamatergic forebrain neurons under the control of Camk2a-Cre. Ctcf ${ }^{\text {loxP/loxP }}$;Camk2a-Cre ${ }^{+}(\mathrm{Ctcf} \mathrm{CKO})$ mice of both sexes were viable and exhibited profound deficits in spatial learning/memory, impaired motor coordination, and decreased sociability by 4 months of age. Ctcf CKO mice also had reduced dendritic spine density in the hippocampus and cerebral cortex. Microarray analysis of mRNA from CtcfCKO mouse hippocampus identified increased transcription of inflammation-related genes linked to microglia. Separate microarray analysis of mRNA isolated specifically from $\operatorname{tcf} C$ CKO mouse hippocampal neurons by ribosomal affinity purification identified upregulation of chemokine signaling genes, suggesting crosstalk between neurons and microglia in Ctcf CKO hippocampus. Finally, we found that microglia in CtcfCKO mouse hippocampus had abnormal morphology by Sholl analysis and increased immunostaining for $\mathrm{CD} 68$, a marker of microglial activation. Our findings confirm that $C t c f \mathrm{KO}$ in postnatal neurons causes a neurobehavioral phenotype in mice and provide novel evidence that CTCF depletion leads to overexpression of inflammation-related genes and microglial dysfunction.

Key words: behavior; chemokine; CTCF; dendritic spine; inflammation; microglia

Significance Statement

CCCTC-binding factor (CTCF) is a DNA-binding protein that organizes nuclear chromatin topology. Mutations in CTCF cause intellectual disability and autistic features in humans. CTCF deficiency in embryonic neurons is lethal in mice, but mice with postnatal CTCF depletion are less well studied. We find that mice lacking Ctcfin Camk2a-expressing neurons (CtcfCKO mice) have spatial learning/memory deficits, impaired fine motor skills, subtly altered social interactions, and decreased dendritic spine density. We demonstrate that Ctcf CKO mice overexpress inflammation-related genes in the brain and have microglia with abnormal morphology that label positive for $\mathrm{CD} 68$, a marker of microglial activation. Our findings suggest that inflammation and dysfunctional neuron-microglia interactions are factors in the pathology of CTCF deficiency.

\section{Introduction}

CCCTC-binding factor (CTCF) is a ubiquitously expressed, 11 zinc finger DNA-binding domain protein encoded by CTCF in humans and Ctcf in mice. CTCF binds throughout the genome (Wang et al., 2012) at the borders of megabase-scale, 3D chromatin structures called topological associated domains (TADs) 
(Dixon et al., 2012). CTCF-organized TADs control gene expression by packaging enhancers and promoters into distinct spatial compartments within cell nuclei (Merkenschlager and Nora, 2016). CTCF regulates expression of CNS genes, including homeobox (Hox) gene clusters, in developing spinal cord motor neurons (Narendra et al., 2015) and at protocadherin $(P c d h)$ gene clusters in the brain (Golan-Mashiach et al., 2012). Knock-down of CTCF disrupts TAD structure, leading to widespread dysregulation of gene expression (Zuin et al., 2014).

CTCF is linked to neurodevelopmental disorders. Individuals with haploinsufficiency for CTCF have a neuropsychiatric phenotype characterized by delayed acquisition of developmental milestones, intellectual disability, and autistic features (Gregor et al., 2013). CTCF also regulates transcription at FMR1, the locus for Fragile X syndrome, a common cause of intellectual disability and autism spectrum disorder (ASD) (Lanni et al., 2013), and binds at sites linked to a broad group of neurodevelopmental disorders (Strong et al., 2015; Meguro-Horike et al., 2011; Mégarbané et al., 2013). In addition, mutations in genes encoding CTCF-interacting proteins cause Cornelia de Lange syndrome (Peters et al., 2008) and Rett syndrome (Kernohan et al., 2010).

In addition to CTCF, inflammation is widely thought to contribute to neurodevelopmental disorders including ASD (Estes and McAllister, 2015). ASD-associated mutations occur in genes encoding immune system components (Estes and McAllister, 2015) and transcriptional profiling of ASD brain tissue enriches for immunity genes (Voineagu et al., 2011). ASD is linked to immune dysfunction including anti-brain autoantibodies (Cabanlit et al., 2007), altered serum and CSF cytokine profiles, and aberrant cell-mediated immune responses (Estes and McAllister, 2015). ASD-associated microglial abnormalities include: increased numbers (Vargas et al., 2005; Tetreault et al., 2012), abnormal morphologies (Morgan et al., 2010), and hyperactivation (Suzuki et al., 2013) of these cells. CTCF regulates the expression of genes encoding the inflammatory mediator interleukin-21 (Park et al., 2016) and human leukocyte antigens (Raj et al., 2016), indicating a connection between CTCF and inflammation.

Although constitutive Ctcfknock-out (KO) mice are lethal in the preimplantation phase of embryogenesis (Moore et al., 2012), conditional $\mathrm{Ctcf} \mathrm{KO}$ mice have provided valuable information about the role of CTCF in neural development. Both Foxg1-Cre mediated deletion of Ctcf in the embryonic neuroepithelium and Nestin-Cre mediated deletion of Ctcf in embryonic neuroprogenitor cells cause massive apoptosis that is lethal embryonically (Foxgl-Cre) or at delivery (Nestin-Cre) (Watson et al., 2014). Conditional Ctcf KO in embryonic postmitotic projection neurons under the control of Nex-Cre produces mice that have aberrant dendritic arborization, fewer dendritic spines, and die by 4 weeks of age (Hirayama et al., 2012). Thus, during embryogenesis CTCF is a survival factor for neural progenitor cells and later contributes to dendritic microstructure development in postmitotic neurons. However, both the effect of depleting CTCF postnatally and the role of CTCF in neuronal function in adult animals are less well studied.

We explored the role of CTCF in neurons of adult animals by crossing mice carrying a loxP-flanked allele of Ctcf (Heath et al.,

Institute of Child Health and Human Development of the NIH Grant U54HD087011). The content is solely the responsibility of the authors and does not necessarily represent the official views of the NIH.

The authors declare no competing financial interests.

Correspondence should be addressed to Dr. Jeffrey Milbrandt, Washington University School of Medicine, Department of Genetics, Campus Box 8232, 4523 Clayton Avenue, St. Louis, M0 63110. E-mail: jmilbrandt@wustl.edu.

DOI:10.1523/JNEUROSCI.0936-17.2017

Copyright $\odot 2018$ the authors $\quad 0270-6474 / 18 / 380201-20 \$ 15.00 / 0$
2008) with mice transgenic for Camk2a-Cre, which express Cre recombinase in postmitotic, glutamatergic neurons of CA1 hippcampus and layer V cerebral cortex (Tsien et al., 1996). The resulting $C t c f^{\text {loxP/loxP }}$;Camk2a-Cre mice (hereafter $C t c f C K O$ ) developed neurobehavioral impairments, reduced dendritic spine density, upregulation of inflammation-related gene expression, and abnormal microglia. Our data show that: (1) CTCF deficiency in adult mice causes behavioral deficits, (2) CTCF is required outside of development to maintain a normal neuronal gene expression profile, and (3) neuronal CTCF deficiency leads to an aberrant microglia phenotype.

\section{Materials and Methods}

Mouse husbandry. All animal procedures were performed in compliance with the National Institutes of Health's Guide for the Care and Use of Laboratory Animals and approved by the Animal Studies Committee in the Division of Comparative Medicine at Washington University School of Medicine in St. Louis (Protocol \#20140044). Mice were housed in a temperature-controlled barrier facility maintained at $24^{\circ} \mathrm{C}$. Facility lighting was kept on a fixed $12 \mathrm{~h}$ light and $12 \mathrm{~h}$ dark cycle. Mice had access to fresh water and rodent chow \#5001 (Purina) ad libitum. Mouse health was monitored daily by a staff of licensed veterinarians. Mouse lines used in this experiment have been described previously and include: $C t c f^{\text {loxP }}$ (Heath et al., 2008), Camk2a-Cre (Tsien et al., 1996; The Jackson Laboratory stock \#005359, RRID:IMSR_JAX:005359), Gt(ROSA)26Sor ${ }^{\text {tm9(CAG - tdTomato)Hze }}$ (Madisen et al., 2010; The Jackson Laboratory stock \#007909, RRID: IMSR_JAX:007909), Thy1-YFP ${ }^{\text {HJrs/J }}$ (Feng et al., 2000; The Jackson Laboratory stock \#003782, RRID:IMSR_JAX:003782), Rpl22 ${ }^{\text {tm1.1Psam/J }}$ (Sanz et al., 2009; The Jackson Laboratory stock \#011029, RRID:IMSR_ JAX:011029), and CX3cr1 ${ }^{\text {tmlLitt/J }}$ (Jung et al., 2000; The Jackson Laboratory stock \#005582, RRID:IMSR_JAX:005582). We intercrossed Ctcf $f^{\text {loxP }}$ and Camk2a-Cre mice to generate Ctcf loxP/loxP $;$ Camk2a-Cre ${ }^{+}$(Ctcf $\mathrm{CKO})$ and $C t c f^{\text {loxP/loxP }}$; Camk2a-Cre ${ }^{-}$(control) mice. We intercrossed Ctcf ${ }^{\text {loxP }}$, Camk2a-Cre, and Thyl-YFP ${ }^{\mathrm{HIrs} / \mathrm{I}}$ mice to generate $C t c f^{\text {loxP/loxP; }}$ Camk2a-Cre ${ }^{+}$; Thyl-YFP ${ }^{\mathrm{HJrs} / J+}$ (Ctcf CKO;YFP) and Ctcf loxP/loxP; Camk2a-Cre ${ }^{-}$;Thy1-YFP ${ }^{\mathrm{HIr} s / \mathrm{J}+}$ (control;YFP) mice. Similarly, we intercrossed Ctcf loxP, Camk2a-Cre, and Rpl22 ${ }^{\mathrm{tm} 1.1 \mathrm{Psam} / \mathrm{J}}$ mice to generate $C t c f^{\text {loxP/loxP }} ; C_{\text {Camk2a-Cre }}{ }^{+} ;$Rpl22 $^{\text {tml.1Psam/J }+}$ (Ctcf CKO;RiboTag) and Ctcf ${ }^{\text {loxP/loxP }} ;$ Camk2a-Cre ${ }^{-} ;$Rpl22 $2^{\text {tm1.1Psam/J }}+$ (control;RiboTag) mice. We verified the extent of expression of Cre in our Camk2a-

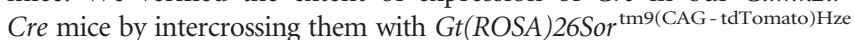
mice to generate $\mathrm{Gt}(\mathrm{ROSA}) 26 \mathrm{Sor}^{\mathrm{tm} 9(\mathrm{CAG}-\mathrm{tdTomato}) \mathrm{Hze}} ; \mathrm{Camk}^{\mathrm{a} a-C r e^{+}}$ (tdTomato;Camk2a-Cre) mice. We verified that Cx3crl and Camk2a expression patterns were nonoverlapping by intercrossing tdTomato; Camk2a-Cre and $\mathrm{C} \times 3 \mathrm{cr} 1^{\mathrm{tm} 1 \mathrm{Litt} / \mathrm{I}}$ mice to generate animals with all three

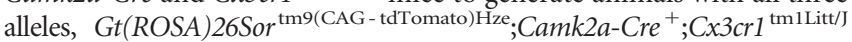
(Cx3crl-EGFP; tdTomato;Camk2a-Cre mice). Both male and female animals were used for all experiments.

Mouse behavioral analysis. We performed behavioral analysis of two cohorts of $C t c f C K O$ and control mice. Testing was conducted on the first (adult) cohort of $9 \mathrm{Ctcf} \mathrm{CKO}$ and 10 control mice, including 11 females and 9 males, at 3-4 months of age. Mice were evaluated on a $1 \mathrm{~h}$ locomotor activity test, a battery of sensorimotor measures, the Morris water maze (MWM), and the social approach test, in that order. Testing of the second (adolescent) cohort of 10 Ctcf CKO ( 5 males, 5 females) and 10 control mice ( 6 males, 4 females) occurred at 6-8 weeks of age. These mice were evaluated on a $1 \mathrm{~h}$ locomotor activity test, a battery of sensorimotor measures, and the MWM, in that order.

The $1 \mathrm{~h}$ locomotor activity test was conducted during a $1 \mathrm{~h}$ session inside transparent $47.6 \times 25.4 \times 20.6 \mathrm{~cm}$ high polystyrene enclosures as described previously (Wozniak et al., 2004). Computerized photobeam instrumentation was used to measure ambulatory activity and exploration including total ambulations (whole-body movements), number of vertical rearings, and time spent, distance traveled, and entries made into a central $33 \times 11 \mathrm{~cm}$ zone.

The sensorimotor battery was performed as described previously (Wozniak et al., 2004) and consisted of the ledge and platform tests (to evaluate balance and fine motor coordination); the pole, $60^{\circ}$ inclined 
screen test, and $90^{\circ}$ inclined screen test (to assess agility); the inverted screen test (to assess strength); and the walking initiation test (to assess movement initiation).

The MWM was performed as described previously (Wozniak et al., 2007 ) in a 118-cm-diameter pool of opaque water monitored by a computerized video tracking and recording system (ANY-maze; Stoelting, RRID:SCR_014289) that computed escape path length and latency to reach the target platform and calculated swimming speed, platform crossings, and time spent in each quadrant of the pool. Testing included cued (visible platform marked by a red tennis ball on a pole), place (submerged platform obscured from view), and probe (platform absent) trials. Both cued and place trials occurred in 2 blocks of 2 trials daily ( 4 trials per day), with a $2 \mathrm{~h}$ break between blocks. Each trial lasted a maximum of $60 \mathrm{~s}$ and was followed by a $60 \mathrm{~s}$ intertrial interval, during which the mouse was allowed to remain on the platform for the first $30 \mathrm{~s}$. Cued trials occurred over 2 consecutive days. Salient spatial cues were not present in the room during the cued trials and the platform location varied from trial to trial to train the mice to navigate to the platform but minimize spatial learning during this phase of testing. Place trials were initiated $3 \mathrm{~d}$ later and occurred over 5 consecutive days. Spatial cues were prominently displayed during these trials to encourage spatial (hippocampal-dependent) learning. The probe trial was conducted $1 \mathrm{~h}$ after the last place trial on the fifth day. For the probe trial, spatial cues were again prominently displayed, but the escape platform was completely removed from the pool. The mouse was placed in the pool starting from the quadrant diagonal to the last location of the escape platform and allowed to search the pool for $60 \mathrm{~s}$ while time spent in each quadrant and the number of crossings over the previous location of the platform was recorded.

The general procedures for conducting the social approach test were similar to our previously published methods (Dougherty et al., 2013), which were adapted from earlier works (Moy et al., 2004; Silverman et al., 2011). The test involved quantifying sociability, or the tendency to initiate social investigation of an unfamiliar conspecific (stimulus mouse) contained in a small withholding cage, compared with the investigation of an empty withholding cage. The apparatus was a rectangular 3-chambered Plexiglas box (each chamber measuring $19.5 \mathrm{~cm} \times 39 \mathrm{~cm} \times 22 \mathrm{~cm}$ ) containing Plexiglas dividing walls with rectangular openings $(5 \times 8 \mathrm{~cm})$ covered by sliding Plexiglas doors. A small stainless-steel withholding cage $(10 \mathrm{~cm} \mathrm{~h} \times 10 \mathrm{~cm}$ diameter; Galaxy Pencil/Utility Cup; Spectrum Diversified Designs) was used to sequester a stimulus mouse. The withholding cage consisted of vertical bars, which allowed for restricted social interactions between the mice but prevented fighting and sexual contact, and one cage was located in each outer chamber. A digital video camera connected to a PC loaded with a tracking software program (ANY-maze; Stoelting) recorded the movement of the mouse within the apparatus and quantified time spent in each chamber and in investigation zones surrounding the withholding cages, the latter being scored when the head of the mouse intersected the zones. The investigation zones were $12 \mathrm{~cm}$ in diameter, encompassing $2 \mathrm{~cm}$ around the withholding cages. The test sequence consisted of three consecutive $10 \mathrm{~min}$ trials. For the first trial, each mouse was placed in the middle chamber with the doors to the outer chambers shut to become acclimated to the apparatus. During the second trial, the mouse was allowed to investigate and habituate to all three chambers freely, including the empty withholding cages (Page et al., 2009; Naert et al., 2011; Pobbe et al., 2012). The third (test) trial assessed sociability exhibited toward an unfamiliar stimulus mouse versus the familiar, empty withholding cage by placing an unfamiliar, age- and gender-matched stimulus mouse in one withholding cage while the other was left empty. The test mouse was allowed to explore the apparatus freely and investigate the novel mouse in the withholding cage. The locations of the stimuli mice in the outer chambers were counterbalanced within and across groups.

Mouse electroencephalography. Adult (3-4 months old) control and Ctcf CKO mice ( $n=6 /$ genotype) underwent continuous video-EEG monitoring using standard methods for implanting epidural electrodes and performing continuous video-EEG recordings, as described previously (Erbayat-Altay et al., 2007). Briefly, mice were anesthetized with isoflurane and placed in a stereotaxic frame. Five epidural screw elec- trodes were surgically implanted on the skull and secured using dental cement. Video and EEG data were acquired simultaneously with a stellate video-EEG acquisition system. Continuous 24/7 video-EEG data were obtained for 6 weeks from each mouse and were analyzed for seizures or interictal epileptiform abnormalities. Electrographic seizures were defined as a characteristic pattern of discrete periods of rhythmic spike discharges that evolved in frequency and amplitude lasting at least $10 \mathrm{~s}$.

Western blot. We harvested hippocampus and cerebral cortex from adult (3-6 months old) Ctcf CKO and control mice $(n=18$ animals per genotype for hippocampus; $n=26$ animals per genotype for cerebral cortex). Tissues were snap frozen in liquid nitrogen and homogenized in lysis buffer containing $50 \mathrm{~mm}$ Tris $\mathrm{pH} 7.4,150 \mathrm{~mm} \mathrm{NaCl}, 1 \%$ Triton $\mathrm{X}-100,0.5 \%$ sodium deoxycholate, $0.1 \%$ SDS, 1 mM PMSF, 1 mm sodium orthovanadate, and complete protease inhibitor mixture (SigmaAldrich). The lysates were cleared by centrifugation at $13,800 \times g$ for 10 $\min$ at $4^{\circ} \mathrm{C}$ and total protein was quantified using the MicroBCA assay kit (Pierce). Proteins were separated by SDS-PAGE and transferred to nitrocellulose membrane (GE Life Sciences). Membranes were blocked for $1 \mathrm{~h}$ at room temperature in 5\% nonfat dry milk in Tris-buffered saline with $0.05 \%$ Tween (TBST) and incubated overnight at $4^{\circ} \mathrm{C}$ with either $1: 1000$ anti-CTCF antibody (Cell Signaling Technology catalog\#2899, RRID: AB_2086794) in TBST plus 5\% bovine serum albumin or 1:1000 antiGAPDH antibody (Cell Signaling Technology catalog\#5174, RRID: AB_10622025) in TBST plus 5\% nonfat dry milk. The next day, membranes were washed with TBST and incubated with 1:5000 goat anti-rabbit conjugated to horseradish peroxidase (GE Life Sciences) in TBST for $2 \mathrm{~h}$ at room temperature before a final wash. Membranes were developed with Western Bright Quantum HRP substrate (Advansta). Blots were imaged on a G:Box gel documentation system (Syngene) running GeneSys acquisition software (RRID:SCR_015770). Tag image file format-style images were exported to the Fiji build of ImageJ (RRID:SCR_002285) and analyzed using the Gel Analyzer function.

Total mRNA isolation. Brain regions were harvested from both male and female adult (3-6 months old) Ctcf CKO and control mice after behavioral testing. Tissues were snap frozen in liquid nitrogen and homogenized in TRIzol (Life Technologies) using a bullet blender (Next Advance). The TRIzol procedure was performed according to the manufacturer's instructions. RNA was purified on NucleoSpin RNA columns with on-column DNase digestion (Machery-Nagel) according to the manufacturer's intructions. RNA concentration was determined using a NanoDrop (Thermo Scientific) and RNA integrity was verified using an Agilent Technologies bioanalyzer and either RNA 6000 nano or pico chips, depending on the concentration of the sample. Only high-quality RNA samples, defined as having both a $260 / 280 \mathrm{~nm}$ aborbance ratio of 1.8 to 2.1 on the NanoDrop and RNA integrity number $>8.0$ on the Bioanalyzer, were used in downstream microarray and qRT-PCR applications.

Histology, immunofluorescent antigen detection, and microscopy. Threeto 6-month-old mice were anesthetized with isoflurane and transcardially perfused with either 4\% paraformaldehyde in PBS or, for Timm staining, with $0.9 \%$ sodium chloride, $0.37 \%$ sodium sulfide sulfide solution, and 4\% formaldehyde. Brains were dissected and fixed overnight in $4 \%$ paraformaldehyde in PBS, cryopreserved in 30\% sucrose in PBS, and embedded in Tissue-Tek optimal cutting temperature compound (Sakura Finetek). Then, 40- $\mu$ m-thick sections were cut on a cryostat and mounted on Fisherbrand Superfrost/Plus microscope slides, which were air-dried and stored at -20C. Nissl staining was performed with cresyl violet (Sigma-Aldrich) as described previously (Paul et al., 2008). Timm staining was performed as described previously (Guo et al., 2013). Light microscope imaging was performed with a NanoZoomer 2.0-HT digital slide scanner (Hamamatsu). For immunofluorescent antigen detection, frozen sections were washed, antigen retrieved for $30 \mathrm{~min}$ at $80^{\circ} \mathrm{C}$ in 10 $\mathrm{mm}$ tribasic sodium citrate dihydrate, $0.05 \%$ Triton $\mathrm{X}-100, \mathrm{pH} 6$, and blocked in TBST with 10\% normal horse serum and $0.3 \%$ Triton X-100 for $1 \mathrm{~h}$ at room temperature. Sections were incubated with primary antibodies diluted in blocking buffer overnight at $4^{\circ} \mathrm{C}$. After $35 \mathrm{~min}$ washes with PBS, sections were incubated with secondary antibodies diluted in blocking buffer for $1 \mathrm{~h}$ at room temperature. Immunostained sections were mounted with Vectashield hard-set mounting medium with DAPI 
(Vector Laboratories, RRID:AB_2336788). Primary antibodies included the following: 1:100 anti-NeuN (EMD Millipore catalog\#ABN78A4, RRID:AB_10920751), 1:500 anti-glial fibrillary acidic protein (GFAP) (Millipore catalog \#AB5804, RRID:AB_10062746), 1:500 anti-Iba1 (Wako catalog \#019-19741, RRID:AB_839504), 1:200 anti-Ki67 (Vector Laboratories catalog\#VP-K451, RRID:AB_2314701), 1:150 anti-Caspase-3 D175A (Cell Signaling Technology catalog\#9661, RRID:AB_2341188), 1:400 anti-S100- $\beta$ (S100B; Dako catalog\#Z0311, RRID:AB_10013383), 1:200 anti-CD68 (Bio-Rad catalog\#MCA1957GA, RRID:AB_324217). Secondary antibodies included 1:500 anti-rabbit Alexa Fluor 488 (Thermo Fisher catalog \#A11034, RRID:AB_2576217) and 1:500 antirabbit Cy3 (Jackson Immunoresearch catalog\#111-165-144, RRID: AB_2338006). Confocal images were captured with a Leica DMI 4000 confocal microscope equipped with diode $405 \mathrm{~nm}$ and solid-state 488 and $561 \mathrm{~nm}$ lasers and $20 \times, 63 \times$, and $100 \times$ oil-immersion objectives. For each stain and antibody described above, at least eight sections from each of three to six brains per genotype were examined. Representative sections are displayed. The LASX software analysis suite (Leica) was used to generate maximum intensity projections of each image. For each antibody, a uniform threshold was applied to all images from both genotypes. Thresholded images were binarized and imported into the Fiji build of ImageJ (RRID:SCR_002285), which was used to calculate the area of the binary image equivalent to the area of the image occupied by a given antibody. This value was divided by the total image area to determine a percentage area. For CD68, we divided by the Iba-1-positive image area to determine the percentage microglial area occupied by CD68. For quantification of dendritic spines, we collected full-thickness confocal $z$-stacks of apical dendrites using $100 \times$ magnification, $512 \times$ 512 resolution, 3 frame average, and $140 \mathrm{~nm} z$-step size $(n=10-20$ image stacks per animal, 3 animals per genotype). We selected individual dendrites ( $n=50$ dendrites/animal for hippocampus, $n=28-32$ dendrites/ animal for cortex) of at least $10 \mu \mathrm{m}$ length, generated mean intensity projection images using the LASX software analysis suite (Leica), and counted the number of spines manually, which we report as spines per micrometer of dendrite length. Individuals blinded to genotype performed all counting. We evaluated the patterns of enhanced green fluorescent protein (EGFP) and red fluorescent tdTomato protein in the hippocampus and cerebral cortex of Cx3cr1-EGFP; tdTomato;Camk2aCre mice using 10 images of each tissue, which were collected from a total of three animals.

RiboTag isolation of Camk2a-Cre expressing cell-specific mRNA: The RiboTag isolation method was performed as described previously (Sanz et al., 2009). Briefly, hippocampus was dissected rapidly from naive adult mice ( 2 males and 2 females, each at least 3 months old) and homogenized in polysome buffer consisting of $50 \mathrm{~mm}$ Tris, $\mathrm{pH} 7.5,100 \mathrm{~mm} \mathrm{KCl}$, $12 \mathrm{~mm} \mathrm{MgCl} 2,1 \%$ Nonidet P-40, 1 mm DTT, 200 U/ml Rnasin Plus (Promega), $200 \mathrm{U} / \mathrm{ml}$ Superasin (Life Technologies), $100 \mu \mathrm{g} / \mathrm{ml}$ cyclohexamide, $1 \mathrm{mg} / \mathrm{ml}$ heparin, and $1 \times$ complete protease inhibitor tablet mixture (Sigma-Aldrich). Samples were centrifuged at $10,000 \times g$ for 10 $\min$ at $4^{\circ} \mathrm{C}$. The supernatants were collected and immunoprecipitated with anti-HA antibody (HA.11, BioLegend catalog \#901502, RRID: $\mathrm{AB} \_2565007$ ) overnight at $4^{\circ} \mathrm{C}$ and, the next day, antibody-antigen-RNA complexes were recovered with Dynabeads protein G. The beads were washed 3 times for 5 min each in high-salt buffer consisting of $50 \mathrm{~mm}$ Tris, $\mathrm{pH}$ 7.5, $300 \mathrm{~mm} \mathrm{KCl,} 12 \mathrm{~mm} \mathrm{MgCl}_{2}$, 1\% Nonidet P-40, 1 mм DTT, and $100 \mu \mathrm{g} / \mathrm{ml}$ cyclohexamide. Then, the antigen-antibody-RNA complexes were eluted with RA1 buffer (Machery-Nagel) containing 1:100 $\beta$-mercaptoethanol. RNA was recovered from the eluate using NucleoSpin RNA columns (Machery-Nagel) with on-column DNase digestion. RNA concentration was determined using a NanoDrop (Thermo Scientific) and RNA integrity was verified using an Agilent Technologies nioanalyzer and either RNA 6000 nano or pico chips, depending on the concentration of the sample. The remainder of each sample was frozen at $-80^{\circ} \mathrm{C}$ until further use.

$q R T-P C R$. We used the qScript cDNA synthesis kit (Quanta Bio) to generate cDNA from $10 \mathrm{ng}$ samples of RiboTag-isolated RNA or $500 \mu \mathrm{g}$ of TRIzol-isolated RNA. qRT-PCR was performed using PerfeCTa SYBR Green FastMix (Quanta Bio) on an ABI Prism 7900HT Sequence Dectection System (Applied Biosystems). All qRT-PCRs were run using a standard program: $2 \mathrm{~min}$ at $50^{\circ} \mathrm{C}, 10 \mathrm{~min}$ at $95^{\circ} \mathrm{C}$, followed by 40 cycles of $15 \mathrm{~s}$ at $95^{\circ} \mathrm{C}, 30 \mathrm{~s}$ at $60^{\circ} \mathrm{C}$, and $30 \mathrm{~s}$ at $72^{\circ} \mathrm{C}$. The following primer pairs were used: Gapdh 5'-AATGTGTCCGTCGTGGATCT-3' forward and 5'-GTTGAAGTCGCAGGAGACAA-3' reverse; C1ql1 5' -CCAACCTAG GCAACAACTAC-3' forward and 5'-GTAGTTCTGGTCTGCATCCT-3' reverse; Ccl17 5'-GATGCCATCGTGTTTCTGAC-3' forward and 5'CCAATCTGATGGCCTTCTTC-3' reverse; Tnfrsf $12 a 5^{\prime}$-GAGAAAAGT TTACTACCCCCATAGAG- $3^{\prime}$ forward and $5^{\prime}$-GGCTGACTCCAGAA TGAATGAA-3' reverse; Grk4 5'-GGTGCATTGAATTCTTGGATG-3' forward and 5'-GGGACTTCTGACTTCTCTTTG-3' reverse; Nefh 5' TGCCGCTTACAGAAAGCTC-3' forward and $5^{\prime}$-GCGTGGATATGG AGGGAATTT-3' reverse; Tlr2 5' -ACCTCAGACAAAGCGTCAAA-3' forward and 5' ${ }^{\prime}$-TTGCTGAAGAGGACTGTTATGG-3' reverse; Ptgs2 5'-CCAGAGCAGAGAGATGAAATAC- 3 ' forward and $5^{\prime}$-TCCTTCT CTCCTGTAAGTTCT-3' reverse; Ccl2 5' -CTCTCTTCCTCCACCACC AT-3' forward and 5'-CGTTAACTGCATCTGGCTGAG-3' reverse; $\mathrm{Ccl} 35^{\prime}$-TTCTCTGTACCATGACACTCTGC-3' forward and $5^{\prime}$-CG TGGAATCTTCCGGCTGTAG-3' reverse; Ccl9 5' ${ }^{\prime}$-ATCACACATGCA ACAGAGACA-3' forward and 5'-TGGAACCCCCTCTTGCTGAT-3' reverse; $C d 83$ 5'-GTTGCTCTTCTCTCTGGTTG-3' forward and 5'CTTGTTCCGTACCAGGTTTAG-3' reverse; Cd14 5' -CCACCGCTG TAAAGGAAAGA-3' and $5^{\prime}$-CCAGAAGCAACAGCAACAAG- $3^{\prime}$ reverse; and Cd52 5' -GGTTGTGATTCAGATACAAACAG- $3^{\prime}$ forward and 5'-GAGGTAGAAGAGGCACATTAAG-3' reverse. We used the standard curve method to quantify gene expression levels, which were normalized to Gapdh expression. For analysis of Ctcf expression, $n=6$ samples per genotype per tissue were used. For analysis of Tlr2, Ptgs2, $\mathrm{Ccl} 2, \mathrm{Ccl} 3, \mathrm{Ccl} 9, \mathrm{Cd} 83, \mathrm{Cd} 14$, and $\mathrm{Cd52}, n=8$ samples per genotype were used. For analysis of C1ql1, Ccl17, Tnfrsf12a, Grk4, and Nefh, $n=12$ samples per genotype were used.

Microarray analysis. For microarray on RNA derived from whole hippocampus tissue, RNA was amplified and reverse transcribed to cDNA using the MessageAmpII kit (Life Technologies) according to the manufacturer's instructions. The amplified cDNA was then fluorescently labeled using the Kreatech ULS kit (Kreatech Diagnostics) according to the manufacturer's instructions. Labeled cDNAs were purified on QIAquick PCR purification columns (Qiagen) and quantified using a NanoDrop spectrophotometer. Then, the labeled cDNAs were hybridized to Agilent Technologies mouse GE $4 \mathrm{x} 44 \mathrm{k}$ v2 microarrays according to the manufacturer's instructions. Slides were scanned on an Agilent Technologies SureScan microarray scanner to detect fluorescence. Gridding and analysis of images was performed using Agilent Technologies Feature Extraction software version 11.5 (RRID:SCR_014963) and the resulting feature (probe)-extracted .txt data for each sample was used for downstream bioinformatic analysis as described below. For analysis of whole hippocampus gene expression by microarray, we used three independent biological replicates per genotype (Ctcf CKO and control). Each biological replicate consisted of a pool of paired hippocampi from 3 individual mice 3-6 months of age. One Ctcf CKO biological replicate was hybridized twice to microarrays to generate a single technical replicate. Data from both technical replicates were combined and averaged for downstream analysis. In a separate microarray experiment, RiboTag-derived RNA from hippocampus ( $n=4$ individual CtcfCKO;RiboTag and Control;RiboTag animals) was processed as described above, except for the following: (1) RNA was amplified and reverse transcribed to cDNA using the WTA2 Complete Whole Transcriptome Amplification Kit (SigmaAldrich); and(2) labeled cDNAs were hybridized to Agilent Technologies SurePrint G3 Mouse GE 8x60k microarrays. Microarray data from all experiments described here was submitted to the ArrayExpress Repository (RRID:SCR_002964; accession number pending; Parkinson et al., 2007).

Bioinformatic analysis of microarray data. Microarray raw data were normalized using IRON: iterative rank order normalization method (Welsh et al., 2013) and analyzed in the R programming environment using the software packages Bioconductor (Huber et al., 2015; RRID: SCR_006442) and limma (Ritchie et al., 2015; RRID:SCR_010943). Results are expressed in terms of fold changes relative to controls and unadjusted $p$-values. We used a less stringent cutoff of $p<0.05$ because we planned to do extensive wet-lab validation of the genes of interest, 

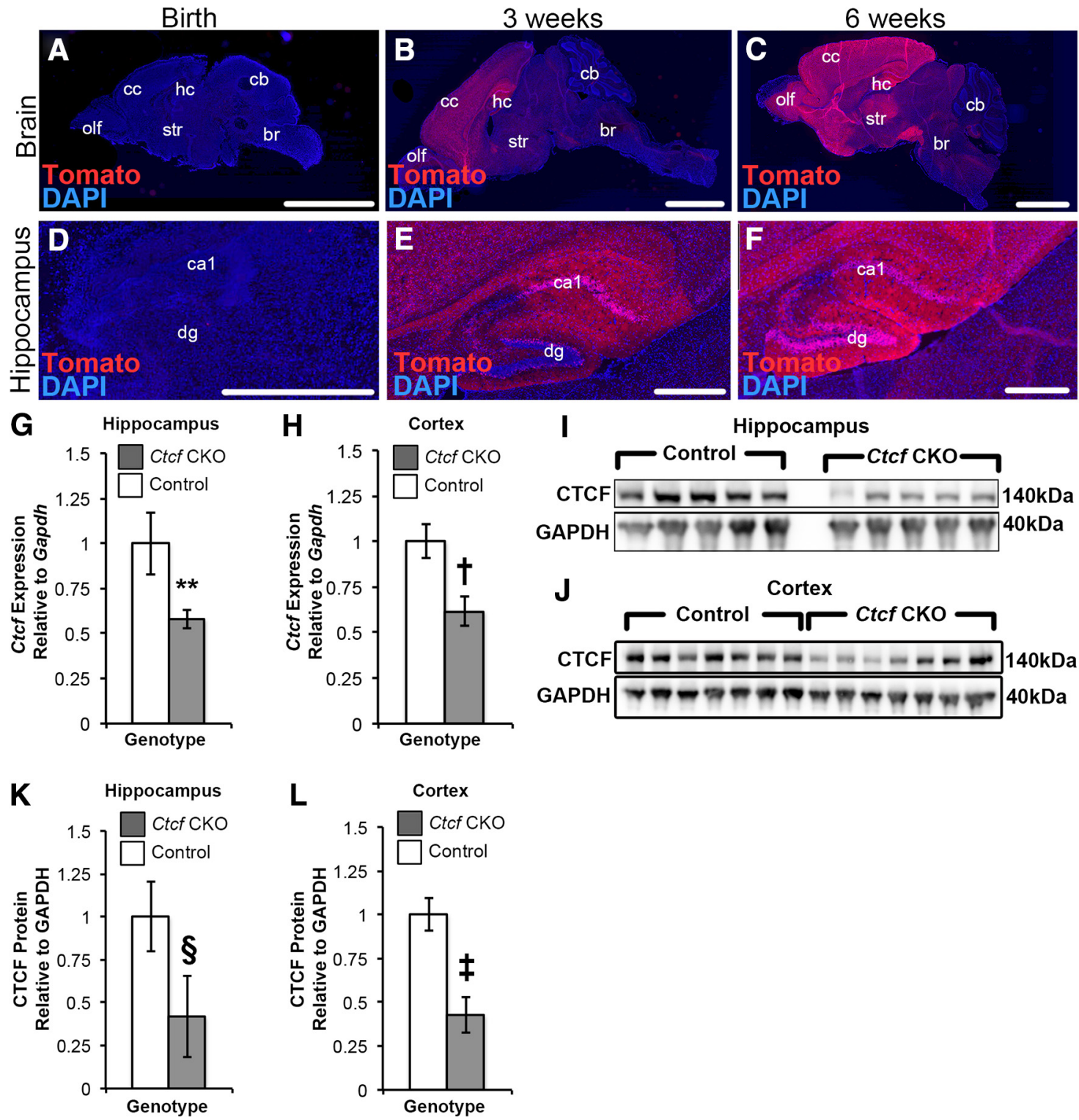

Figure 1. Ctcf CKO mice have depletion of $C t c f m R N A$ and CTCF protein. $\boldsymbol{A}-\boldsymbol{C}$, Midsagittal brain section of tdTomato; Camk2a-Cre ${ }^{+}$mouse at birth $(\boldsymbol{A})$ and at 3 weeks $(\boldsymbol{B})$ and 6 weeks $(\boldsymbol{C})$ of age. $\boldsymbol{D}-\boldsymbol{F}$, Hippocampus of tdTomato; Camk2a-Cre ${ }^{+}$mouse at birth $(\boldsymbol{D})$ and at 3 weeks $(\boldsymbol{E})$ and 6 weeks $(\boldsymbol{F})$ of age. For $\boldsymbol{A}-\boldsymbol{F}$, (re-dependent expression of floxed tdTomato reporter mice indicates $(\boldsymbol{r e}$ activity. Note that no tdTomato fluorescence is visible at birth. By 6 weeks of age, bright red tdTomato-fluorescence is visible in areas where Camk2a-Cre is active, primarily in olfactory bulbs (olf), cerebral cortex (cc), hippocampus (hc), and striatum (str), whereas tdTomato fluorescence is minimal in brainstem (br) and cerebellum (cb). In the hippocampus, tdTomato is prominent in CA1 (ca1) and dentate gyrus (dg). Scale bars: $\boldsymbol{A}-\boldsymbol{C}, 2.5 \mathrm{~mm} ; \boldsymbol{D}-\boldsymbol{F}, 500 \mu \mathrm{m} . \mathbf{G}, \boldsymbol{H}$, CtcfmRNA (normalized to Gapdh) was depleted from the hippocampus $\left(n=6 /\right.$ genotype, $t$ test: $t_{(10)}=3.516$, ${ }^{* *} p=0.0056$; $\boldsymbol{G})$ and cerebral cortex $\left(n=6 /\right.$ genotype, $t$ test: $\left.t_{(10)}=2.714, \dagger p=0.0218 ; \boldsymbol{H}\right)$ of $(t c f C K 0$ mice compared with controls. For both tissues, the CtcfCKO result is displayed relative to the control, which is set to 1 for comparison. $I, J$, Representative Western blots of tissue lysates from control and $(t c f C K 0$ mouse hippocampus $(\boldsymbol{I})$ and cerebral cortex $(\boldsymbol{J})$, which were probed for CTCF (top) and control GAPDH (bottom). We found reduced levels of CTCF protein relative to GAPDH in both tissues from Ctcf CKO mice, where Camk2a-Cre is highly active. This is quantified in $\boldsymbol{K}$ for hippocampus ( $n=$ 18/genotype, Mann-Whitney $U=50, \S p=0.0002$ ) and in $\boldsymbol{L}$ for cerebral cortex $(n=26 /$ genotype, Mann-Whitney $U=125, \neq p<0.0001)$. Values are plotted as means \pm SEM.

keeping in mind that FDR or multiple testing corrections can be too restrictive. Genes with a $> \pm 1.5$ fold change and $p<0.05$ were further analyzed for biological pathway enrichment using EnrichR (Chen et al., 2013; RRID:SCR_001575). We report pathways and biological processes with adjusted $p<0.05$. To generate a profile for the non-neural component, we compared the profiles of the whole hippocampus and RiboTagderived samples and "subtracted" the RiboTag-derived genelist from that of the whole hippocampus.

Flow cytometry. We used flow cytometry to determine the composition of inflammatory cells in the hippocampus and cortex of CtcfCKO mice. First, we isolated microglia from these brain regions, which were dissected, dispersed in homogenization medium (RPMI 1640 medium; Thermo Fisher catalog \#11875085) plus $2 \%$ heat inactivated fetal bovine serum and passed through a disposable $70 \mu \mathrm{m}$ filter to remove debris.
Cells were pelleted by centrifugation at $400 \times g$ for 6 min at $4 \mathrm{C}$ and resuspended in $40 \%$ Percoll in homogenization media. This was carefully layered upon $80 \%$ Percoll in homogenization media and centrifuged at $1000 \times g$ for $20 \mathrm{~min}$ at $18 \mathrm{C}$. The immiscible layer (containing the inflammatory infiltrate) was collected, washed in homogenization medium, and centrifuged at $400 \times g$ for $6 \mathrm{~min}$ at $4 \mathrm{C}$ to pellet the cells. The cells were resuspended in flow cytometry buffer (Hanks' balanced salt solution without calcium, magnesium, or phenol red; Thermo Fisher catalog $\# 14175079,+2 \%$ heat inactivated fetal bovine serum) and blocked with 1:100 purified anti-mouse CD16/32 antibody (BioLegend cata$\log \# 101302$, RRID:AB_312801). The cells were then incubated with 1:100 FITC anti-mouse CD45 antibody (BioLegend catalog \#103108, RRID:AB_312973) and 1:100 PE/Cy7 anti-mouse/human CD11b antibody (BioLegend catalog \#101216, RRID:AB_312799) for $20 \mathrm{~min}$ at $4^{\circ} \mathrm{C}$ 
protected from light. Samples were stained with SYTOX blue (Thermo Fisher catalog \#S348857) at a final concentration of $1 \mu \mathrm{M}$ per the manufacturer's instructions. Cells were analyzed on a FACScan 2 flow cytometer (BD Biosciences) using a gating strategy similar to one described previously to isolate microglia, myeloid, and lymphoid cells (Galatro et al., 2017). All gating strategies incorporated size and doublet discrimination based on forward and side scatter parameters. Data analysis was performed using FlowJo (RRID:SCR_008520) version 10.4 for Macintosh.

Sholl analysis of microglial morphology. We performed Sholl analysis of microglial morphology as described previously (Norris et al., 2014). Briefly, we used confocal microscopy to collect full thickness $63 \times z$-stack images of CA1 hippocampus from 40 - $\mu$ m-thick brain sections that were immunostained for Iba- 1 and DAPI (as outlined above; $n=6$ mice/ genotype, 25 image stacks per animal). $Z$-stacks were collected at $512 \times$ 512 resolution with 3 frame averages for each color channel and $1 \mu \mathrm{m}$ $z$-step size. We used LASX software (Leica) to prepare a maximum intensity projection image of the Iba-1 channel, which we thresholded and exported to the Fiji build of ImageJ (RRID:SCR_002285). For each image, we removed surrounding processes manually in Fiji, thereby isolating a total of 25 microglia per mouse. We used the line segment tool to draw a line from the center of each soma to the tip of its longest process, which provided the maximum process length. We used the Sholl analysis plugin (Ferreira et al., 2014), with the first shell set at $10 \mu \mathrm{m}$ and subsequent shells set at $5 \mu \mathrm{m}$ step sizes, to determine intersections at each Sholl radius. This also provided the critical radius (radius value with the highest number of intersections), the process maxiumum (the highest number of intersections regardless of radius value), and the number of primary branches (intersections at the first Sholl radius). We measured the soma size in Fiji and counted branch endpoints using the cell counter plugin. Finally, we counted microglia per $63 \times$ image stack manually to determine the mean number of microglia per high-power field.

Experimental design and statistical analysis. ANOVA models and $t$ tests were used to analyze the behavioral data. Repeated-measures ANOVA (rmANOVA) models containing one between-subjects variable (genotype) and one within-subjects (repeated measures) variable (e.g., blocks of trials, time blocks) were typically used to analyze certain variables within the activity, spatial learning/memory, and social approach datasets. The Greenhouse-Geisser adjustment of $\alpha$ levels was used for all within-subjects effects containing more than two levels to help protect against violations of sphericity/compound symmetry assumptions underlying rmANOVA models. Pairwise comparisons were also conducted following relevant overall ANOVA effects and were considered significant according to Bonferroni-corrected levels. This involved controlling familywise error rates by dividing 0.05 by the exact number of comparisons that were conducted and using that criterion value to determine significance. Planned within-subjects contrasts were also conducted when appropriate. Data from measures within the sensorimotor battery and some variables from the probe trial were analyzed with $t$ tests. We analyzed mouse weight, qRT-PCR, dendritic spine, flow cytometry, and immunostaining data for NeuN, GFAP, and cleaved caspase- 3 with twotailed $t$ tests. Western blot data and immunostaining data for S100B, Ki67, and CD68 did not follow a normal distribution and was analyzed with the Mann-Whitney $U$ test. We analyzed microglia intersections per Sholl radius using an rmANOVA model with Greenhouse-Geisser adjustment, using genotype as the between-subjects variable and radius as the within-subjects (repeated measures) variable. Other Sholl measurements were evaluated with two-tailed $t$ tests. Number, age, and sex of animals used in individual experiments are noted above.

\section{Results}

To determine the effect of $C t c f \mathrm{KO}$ in postnatal neurons, we bred Ctcf CKO mice by crossing Ctcf ${ }^{\text {loxP }}$ mice (Heath et al., 2008) with Camk2a-Cre mice, which express Cre recombinase in excitatory glutamatergic neurons of layer V cerebral cortex and CA1 hippocampus under the control of the promoter for Camk $2 a$, the gene encoding $\alpha$-calcium-calmodulin-dependent kinase II (Tsien et al., 1996). We verified the appropriate Cre expression pattern by crossing Camk2a-Cre mice with a reporter line carrying a Cre-

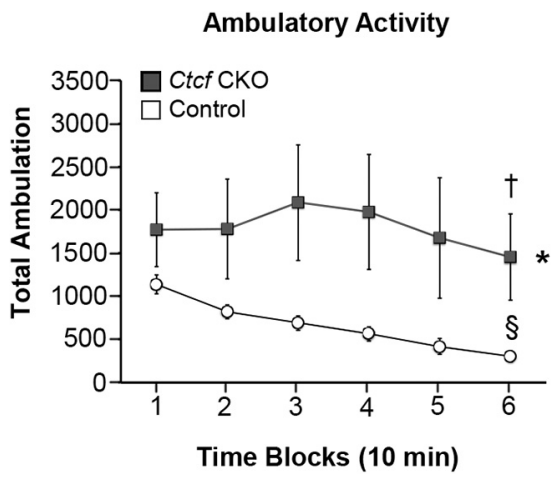

Figure 2. Locomotor activity levels in adult CtcfCKO mice. The general ambulatory (horizontal) activity of adult (3-4 months old) $\operatorname{CtcfCKO}(n=9)$ and control $(n=10)$ mice was evaluated over a $1 \mathrm{~h}$ period. The CtcfCKO mice tended to have more total ambulations (whole-body movements) across the test session compared with the control group and a significant genotype $\times$ time interaction $\left({ }^{*} p=0.037\right)$ suggested that these differences varied with time. Both control and Ctcf CKO groups showed significant decreases in activity from block 1 versus block 6 $(\S p<0.00005$ and $t p=0.022$, respectively). Values are plotted as means \pm SEM.

inducible allele of the cytoplasmic, membrane-targeted, red fluorescent protein tdTomato (Gt(ROSA)26Sor ${ }^{\text {tm9(CAG-tdTomato)Hze }}$ mice; Madisen et al., 2010). At birth, the brains of the resulting Gt(ROSA)26Sor ${ }^{\text {tm9(CAG - tdTomato)Hze }}$;Camk2a-Cre mice (hereafter, tdTomato;Camk2a-Cre mice) had no discernible red fluorescence (Fig. $1 A, D)$. By 3 weeks of age, tdTomato;Camk2a-Cre mice had obvious red fluorescence visible in cortex and hippocampus (Fig. $1 B, E$ ) and, by 6 weeks of age, red fluorescence was robust in cortex and hippocampus (Fig. 1C,F), consistent with previous reports of the chronology of Camk2a-Cre activity (Tsien et al., 1996).

Next, we used qRT-PCR to characterize Ctcf expression levels in the hippocampus (Fig. 1G) and cerebral cortex (Fig. 1H) of $C t c f$ CKO mice, where Camk2a-Cre was highly expressed, as well as in controls ( $n=6$ per genotype per tissue). Ctcf expression was reduced in both tissues in $C t c f$ CKO mice (Fig. $1 G$; hippocampus: $t$ test, $t_{(10)}=3.516,{ }^{*} p=0.0056$; Fig. $1 H$; cerebral cortex: $t$ test, $\left.t_{(10)}=2.714, \dagger p=0.0218\right)$. CTCF protein levels also were visibly diminished in lysates from Ctcf CKO hippocampus (Fig. 1I) and cerebral cortex (Fig. $1 J$ ) compared with the internal control protein GAPDH. We confirmed this difference by quantifying CTCF and GAPDH protein levels in hippocampus (Fig. $1 K, n=18$ / genotype, Mann-Whitney $U=50, \$ p=0.0002$ ) and cerebral cortex (Fig. $1 L, n=26 /$ genotype, Mann-Whitney $U=125$, 邦 $<$ 0.0001). Therefore, we found reductions of Ctcf mRNA and CTCF protein in Ctcf CKO mouse hippocampus and cerebral cortex, both brain regions with high Camk2a-Cre activity.

Ctcf CKO mice were viable for at least 1 year of life, the longest time period at which we evaluated them. The body mass of adult (3-5 months old) Ctcf CKO mice was similar to controls (data not shown, $n=30 /$ genotype, $t$ test, $t_{(58)}=0.3821, p=0.7038$ ). Likewise, the brain mass of adult (3-4 months old) CtcfCKO mice was similar to controls (data not shown, $n=18$ /genotype, $t$ test, $t_{(34)}=0.2167, p=0.8298$ ). At 1 year of age, in contrast to controls, CtcfCKO mice displayed hindlimb clasping, a sign of upper motor neuron dysfunction in the CNS (Guyenet et al., 2010).

To determine whether Ctcf $\mathrm{CKO}$ mice had deficits of motor performance, we evaluated them on a $1 \mathrm{~h}$ locomotor activity test and a battery of 7 sensorimotor tests (Wozniak et al., 2004). In the $1 \mathrm{~h}$ locomotor activity test, the adult (3-4 months old) CtcfCKO mice showed a trend toward higher levels of ambulatory activity during the entire $1 \mathrm{~h}$ test, although rmANOVA showed that the 
Table 1. Behavioral results from adolescent $\mathrm{Ctcf} C \mathrm{CKO}$ mice and controls

\begin{tabular}{|c|c|c|c|c|c|}
\hline Test/variable & $\mathrm{df}$ & F-ratio & $p$-value & CtcfCKO mice (mean \pm SEM) & Control mice (mean \pm SEM) \\
\hline \multicolumn{6}{|l|}{$1 \mathrm{~h} \mathrm{Locomotor} \mathrm{activity}$} \\
\hline Total ambulations & 1,18 & 0.051 & 0.824 & $3910.50 \pm 323.54$ & $4025.70 \pm 394.03$ \\
\hline Number of rears & 1,18 & 0.439 & 0.516 & $494.90 \pm 75.02$ & $554.60 \pm 49.86$ \\
\hline Distance in center area $(\mathrm{cm})$ & 1,18 & 0.021 & 0.886 & $3154.100 \pm 376.97$ & $3085.40 \pm 287.81$ \\
\hline Time in center area (s) & 1,18 & 0.083 & 0.776 & $526.70 \pm 85.54$ & $488.79 \pm 99.56$ \\
\hline Entries into center area & 1,18 & 0.139 & 0.714 & $199.20 \pm 23.87$ & $210.50 \pm 18.66$ \\
\hline \multicolumn{6}{|l|}{ Sensorimotor battery } \\
\hline Walk initiation (s) & 1,18 & 0.077 & 0.784 & $2.01 \pm 0.24$ & $2.13 \pm 0.38$ \\
\hline Time on ledge (s) & 1,18 & 0.012 & 0.915 & $37.44 \pm 6.02$ & $38.32 \pm 5.52$ \\
\hline Time on platform (s) & 1,18 & 3.97 & 0.062 & $39.01 \pm 4.71$ & $52.65 \pm 4.97$ \\
\hline Time to descend pole (s) & 1,18 & 5.223 & $0.035^{*}$ & $20.20 \pm 2.68$ & $47.74 \pm 11.75$ \\
\hline $60^{\circ}$ screen time to top (s) & 1,18 & 1.931 & 0.182 & $18.05 \pm 3.39$ & $25.73 \pm 4.37$ \\
\hline $90^{\circ}$ screen time to top (s) & 1,18 & 0.057 & 0.815 & $28.31 \pm 6.58$ & $26.34 \pm 5.02$ \\
\hline Time on inverted screen (s) & 1,18 & 2.25 & 0.151 & $56.66 \pm 2.23$ & $60.00 \pm 0.00$ \\
\hline Morris water maze trials & \multicolumn{5}{|c|}{ ANOVA results } \\
\hline Cued, escape path length $(\mathrm{cm})$ & \multicolumn{5}{|c|}{$\mathrm{g}: F_{(1,18)}=0.307, p=0.587, \mathrm{~b}: F_{(3,54)}=61.358,{ }^{* * *} p<0.001, \mathrm{~g} \times \mathrm{b}: F_{(3,54)}=0.315, p=0.741$} \\
\hline Cued, escape latency (s) & \multicolumn{5}{|c|}{$\mathrm{g}: F_{(1,18)}=1.231, p=0.282, \mathrm{~b}: F_{(3,54)}=66.530,{ }^{* *} p<0.001, \mathrm{~g} \times \mathrm{b}: F_{(3,54)}=0.491, p=0.619$} \\
\hline Cued, swim velocity $(\mathrm{cm} / \mathrm{s})$ & \multicolumn{5}{|c|}{$\mathrm{g}: F_{(1,18)}=0.275, p=0.607, \mathrm{~b}: F_{(3,54)}^{(3,4)}=14.114,{ }^{* * *} p<0.001, \mathrm{~g} \times \mathrm{b}: F_{(3,54)}=0.119, p=0.907$} \\
\hline Place, escape path length $(\mathrm{cm})$ & \multicolumn{5}{|c|}{$\mathrm{g}: F_{(1,18)}=2.261, p=0.150, \mathrm{~b}: F_{(3,54)}^{(3,4)}=16.482,{ }^{* * *} p<0.001, \mathrm{~g} \times \mathrm{b}: F_{(3,54)}=1.202, p=0.318$} \\
\hline Place, escape latency (s) & \multicolumn{5}{|c|}{$\mathrm{g}: F_{(1,18)}=5.392,{ }^{*} p=0.032, \mathrm{~b}: F_{(4,72)}=9.942,{ }^{* * *} p<0.001, \mathrm{~g} \times \mathrm{b}: F_{(4,72)}=1.968, p=0.132$} \\
\hline Place, swim velocity $(\mathrm{cm} / \mathrm{s})$ & \multicolumn{5}{|c|}{$\mathrm{g}: F_{(1,18)}=3.821, p=0.067, \mathrm{~b}: F_{(4,72)}=16.276,{ }^{* * *} p<0.001, \mathrm{~g} \times \mathrm{b}: F_{(4,72)}=1.890, p=0.147$} \\
\hline Probe, time in target quadrant (s) & \multicolumn{5}{|c|}{$\mathrm{g}: F_{(1,18)}=0.014, p=0.907$} \\
\hline Probe, platform crossings & \multicolumn{5}{|c|}{$\mathrm{g}: F_{(1,18)}=450, p=0.511$} \\
\hline
\end{tabular}

Shown are results from testing adolescent $C t c f C K 0$ and control mice on a $1 \mathrm{~h}$ locomotor activity test, a battery of seven sensorimotor measures, and the Morris water maze. The first column lists the tests conducted and the variables that were analyzed. The second, third, and fourth columns list the degrees of freedom (df), F-ratios, and $p$-values from ANOVAs conducted on the data, respectively. Columns 5 and 6 list the means \pm SEM for each variable from the $C t c f C K 0$ and control groups, respectively. The groups did not differ significantly on any of the locomotor activity variables. The groups also performed similarly on the sensorimotor measures except for the pole test, on which the adolescent $C t c f C K O$ mice exhibited significantly impaired performance. The two groups also performed similarly on all of the variables from the cued, place, and probe trials from the Morris water maze test except for escape latency during the place condition, which may have been affected by differences in swimming speeds.

$g$, Genotype effect; $b$, block effect; $g \times b$, genotype $\times$ block interaction.

${ }^{*} p<0.05,{ }^{* * *} p<0.001$.

main effect of genotype was not significant (Fig. $2 ; F_{(1,17)}=4.16$, $p=0.057)$. However, the analysis revealed a genotype $\times$ time interaction (Fig. $2 ; F_{(5,85)}=3.86,{ }^{\star} p=0.037$ ), where differences were greatest during block $6(p=0.028)$, although these differences were not significant according to Bonferroni correction $(p<0.05 / 6=0.0083)$. In addition, the control and Ctcf CKO groups each showed significant decreases in activity from block 1 versus block 6 (Fig. $2 ; \dagger p<0.00005$ and $\$ p=0.022$, respectively). In addition, we found no differences between the adult $C t c f C K O$ mice and controls with respect to rearing frequency or center-ofthe field variables, including time spent, distance traveled, or number of entries in the center of the test arena (data not shown), suggesting comparable levels of emotionality. Results from testing the adolescent (6-8 weeks old) mice on the $1 \mathrm{~h}$ locomotor activity test showed that the Ctcf CKO mice and controls did not differ significantly on any of the dependent variables (Table 1).

We further evaluated Ctcf CKO mice for deficits in balance, strength, movement initiation, agility, and fine motor coordination with a battery of seven sensorimotor tests (listed in Table 2). Adult CtcfCKO and control mice performed similarly on all three screen tasks. These results and the finding that they showed similar latencies to initiate movement suggest that the CtcfCKO were not impaired in strength, agility, or in executing basic movements. However, the Ctcf CKO did exhibit deficits during tasks requiring balance and fine motor coordination. Specifically, the Ctcf CKO mice spent significantly less time balancing on a narrow, elevated Plexiglas ledge (Table $2 ; t_{(17)}=2.90,{ }^{\star} p=0.010$ ) and on an elevated small circular platform (Table $2 ; t_{(17)}=3.80$, $\left.{ }^{*} p=0.001\right)$ compared with controls. In addition, adult Ctcf CKO mice took significantly longer times to climb down an elevated pole (Table $2 ; t_{(17)}=2.25,{ }^{*} p=0.038$ ), which requires fine motor coordination between the forelimbs and hindlimbs. Un-
Table 2. Performance on a battery of sensorimotor tests of adult Ctcf CKO mice and controls

\begin{tabular}{lrrrrl}
\hline Test & $\begin{array}{l}\text { Control } \\
\text { (mean } \pm \text { SEM) })\end{array}$ & $\begin{array}{l}\text { (tcfCKO } \\
\text { (mean } \pm \text { SEM) })\end{array}$ & \multicolumn{1}{l}{$\begin{array}{l}\text { tstatistic } \\
(\mathrm{df}=17)\end{array}$} & $p$-value & Significance \\
\hline $60^{\circ}$ inclined screen & $30.40 \pm 5.30 \mathrm{~s}$ & $27.10 \pm 6.96 \mathrm{~s}$ & 0.382 & 0.707 & NS \\
$90^{\circ}$ inclined screen & $32.90 \pm 5.27 \mathrm{~s}$ & $30.57 \pm 5.39 \mathrm{~s}$ & 0.308 & 0.762 & $\mathrm{NS}$ \\
$180^{\circ}$ inverted screen & $58.85 \pm 0.77 \mathrm{~s}$ & $53.67 \pm 3.13 \mathrm{~s}$ & 1.688 & 0.110 & $\mathrm{NS}$ \\
Walking initiation & $3.18 \pm 0.83 \mathrm{~s}$ & $7.40 \pm 3.24 \mathrm{~s}$ & -1.322 & 0.203 & $\mathrm{NS}$ \\
Ledge & $55.60 \pm 2.94 \mathrm{~s}$ & $38.53 \pm 5.28 \mathrm{~s}$ & 2.904 & 0.010 & $*$ \\
Elevated platform & $51.00 \pm 3.49 \mathrm{~s}$ & $29.77 \pm 4.43 \mathrm{~s}$ & 3.804 & 0.001 & $*$ \\
Elevated pole & $46.47 \pm 7.55 \mathrm{~s}$ & $77.11 \pm 11.68 \mathrm{~s}$ & -2.250 & 0.038 & $*$
\end{tabular}

Adult CtcfCKO mice have impaired balance and fine motor coordination in tests of sensorimotor function. Behavioral performance of the adult (3-4 months old) $\operatorname{CtcfCKO}(n=9)$ and control $(n=10)$ mice was evaluated on the battery of sensorimotor tests. The first column lists the behavioral test conducted. The second and third columns list the means \pm SEM for controls and CtcfCKO mice, respectively. The fourth column lists the $p$-value obtained for Student's $t$ test using $t_{(17)}$ degrees of freedom (df). The last column indicates the degree of statistical significance. Time to fall from a mesh screen oriented at $60^{\circ}, 90^{\circ}$, and $180^{\circ}$ (inverted) was similar between CtcfCKO and control mice. Animals of both genotypes had similar latency to initiate walking. CtcfCKO mice had difficulty with: balancing on a narrow ledge $\left(t_{(17)}{ }^{*} p=0.010\right)$; balancing on a small, circular, elevated platform $\left(t_{(17)}{ }^{* *} p=0.001\right)$, and climbing down an elevated pole $\left(t_{(17)}{ }^{*} p=0.038\right)$.

NS, Not significant.

${ }^{*} p<0.05,{ }^{* *} p<0.01$.

like adult animals, adolescent $C t c f C K O$ mice performed as well as controls on all sensorimotor measures except the pole test, during which adolescent Ctcf $\mathrm{CKO}$ mice were slower to descend (Table 1). Therefore, at 3-4 months of age, the Ctcf CKO mice exhibited a normal activity level and normal strength, but displayed subtle deficits in balance and fine motor coordination.

We evaluated Ctcf CKO mice for deficits of spatial learning and memory by testing them in the MWM (Morris, 1981) and found that adult (3-4 months old) Ctcf CKO mice had severe performance impairments (Fig. 3, Table 3; the table contains inferential statistics for cued and place trials). A two-way rmANOVA 
A
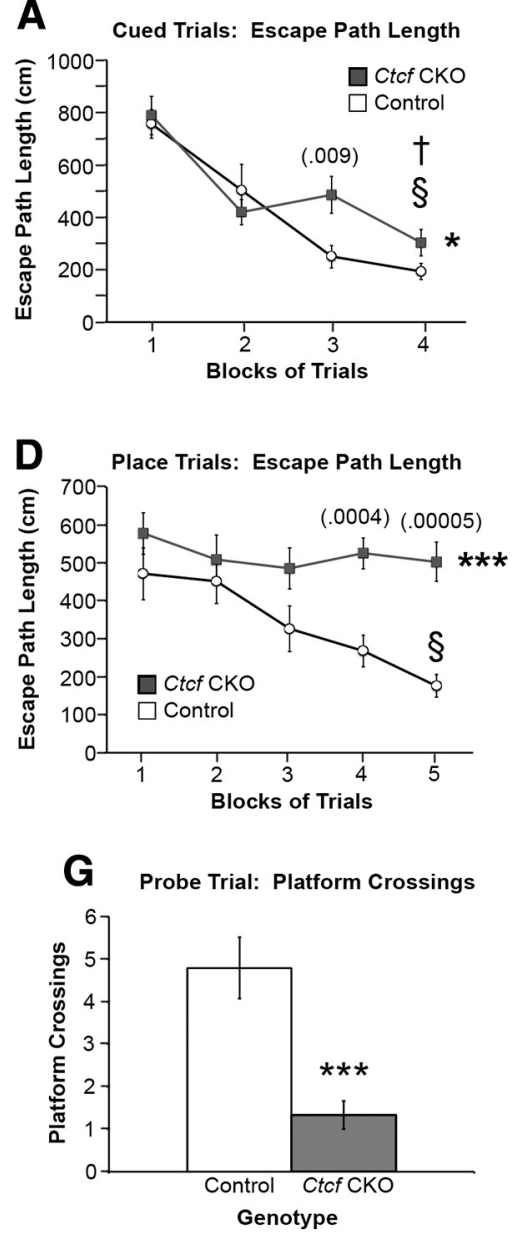

B

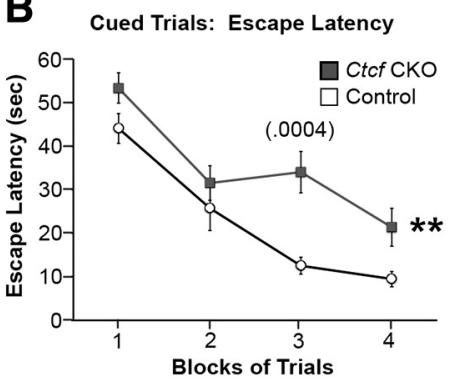

E Place Trials: Escape Latency

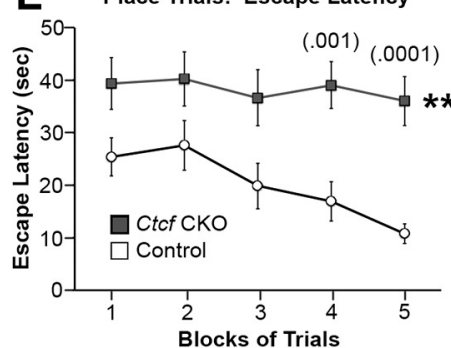

F Place Trials: Swim Velocity
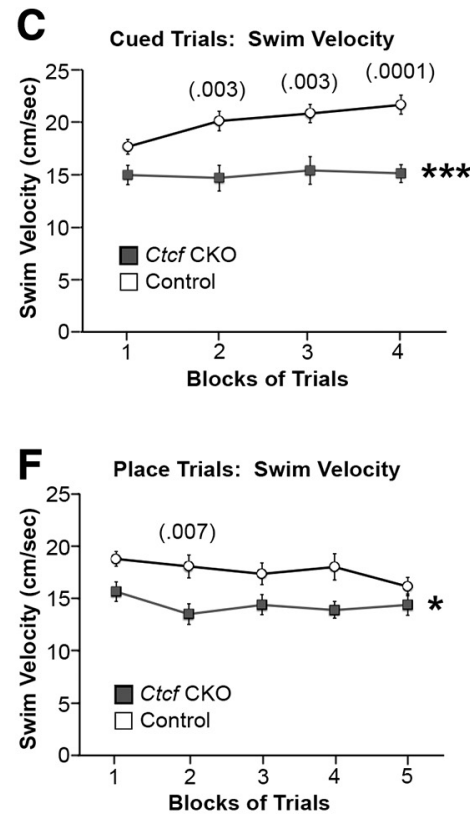
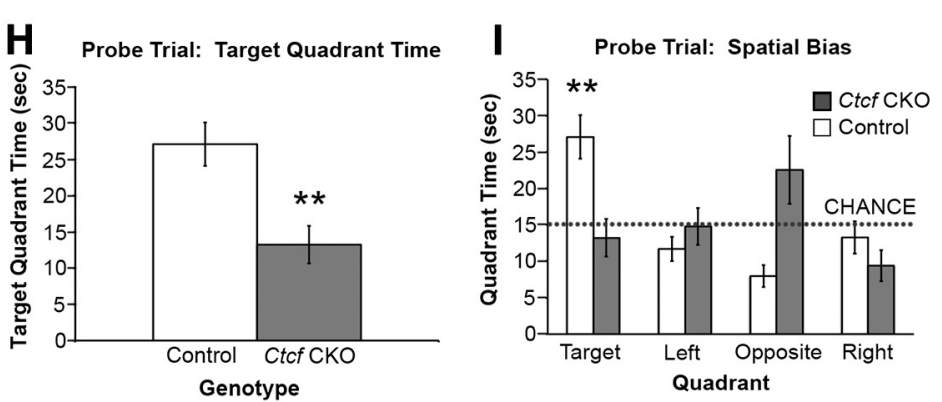

Figure 3. Adult CtcfCKO mice exhibit severe deficits in spatial learning and memory in the MWM. Adult (3-4 months old) $C t c f C K O(n=9)$ and control $(n=10)$ mice were evaluated in the MWM to assess spatial learning and memory. $A$, rmANOVA of the path length data from the cued trials revealed a significant genotype $\times$ blocks of trials interaction $\left({ }^{*} p=0.029\right)$, but path lengths were significantly increased in the CtcfCKO mice for only block $3(p=0.009$ ). Moreover, path lengths were significantly reduced across the cued trials (block 1 vs block 4 ; $\uparrow$ and $\$ p<0.00005$ for each group), suggesting that both the (tcfCKO and control mice showed evidence of cued learning. $B$, rmANOVA of the escape latency data revealed a significant main effect of genotype $\left.{ }^{* *} p=0.004\right)$, but this effect was confounded by differences between the groups in swimming velocities $(\boldsymbol{C})$ thus making the use of latency as a performance variable inappropriate. $\boldsymbol{C}$, Analysis of the swim velocity data showing that the $C t c f C K O$ mice were significantly slower on average across the blocks of trials (genotype effect: ${ }^{* * *} p=0.0003$ ), with significant differences being observed for blocks 2 ( $p=$ $0.003), 3(p=0.003)$, and $4(p=0.0001)$. D . Analysis of the place (spatial learning) trials revealed severe acquisition deficits in the CtcfCK0 mice compared with the control group in terms of path length, (genotype effect: ${ }^{* * *} p=0.0009$ ). Importantly, the control group showed a significant decrease in path length across blocks of trials (block $1 \mathrm{vs}$ block 5: $\$ p=0.0001$ ), whereas the CtcfCK0 mice did not show improved performance during acquisition training, suggesting that the control mice learned the location of the hidden platform, whereas the Ctcf CKO mice failed to do so. Significant between-groups differences were observed for blocks $4(p=0.0004)$ and $5(p<0.00005)$. $E$, Similar findings were observed with regard to escape latency (genotype effect: ${ }^{* *} p=$ 0.001 ) although this effect was confounded once more by the (tcf CKO group again displaying significantly decreased swimming velocities $\left(\boldsymbol{F}\right.$, genotype effect: ${ }^{*} p=0.014 ;$ block 3: $\left.p=0.007\right)$. $\boldsymbol{G}, \boldsymbol{H}$, Retention performance of the (tcf $C$ KO mice was also profoundly impaired during the probe trial, where they made significantly fewer platform crossings $\left({ }^{* * *} p=0.0006 ; \boldsymbol{G}\right)$ and spent significantly less time in the target quadrant $\left({ }^{* *} p=0.003 ; \boldsymbol{H}\right)$ compared with controls. I, Control group exhibited spatial bias for the target quadrant by spending significantly more time in it versus the times spent in each of the other quadrants $\left({ }^{* *} p<0.004\right)$, indicating that they learned and retained the hidden platform location, whereas the CtcfCKO mice did not. Values are plotted as means \pm SEM. For the cued and place trials, $p$-values for relevant individual pairwise comparisons between genotypes are shown within parentheses for individual blocks.

of the path length data from the cued (visible platform location) trials (Fig. $3 A$ ) yielded a significant genotype $\times$ blocks of trials interaction (Fig. $3 A ;{ }^{\star} p=0.029$ ), but this effect appeared to be due mainly to significantly longer path lengths for the Ctcf CKO mice for only block 3 ( $p=0.009)$. Moreover, within-subjects contrasts indicated that both groups exhibited significantly decreased path lengths across the cued trials (Fig. $3 A$; block 1 vs block 4 ; $\dagger$ and $\$ p<0.00005$ for each group), suggesting that both the Ctcf CKO and control mice showed evidence of learning to swim to the cued platform locations. rmANOVA of the escape latency data (Fig. $3 B$ ) revealed a significant genotype effect (Fig. $3 B ;{ }^{* *} p=0.004$ ), but analysis of the swim velocity data (Fig. $3 C$ ) showed that the latency data were artifactually exaggerated by significantly slower swimming velocities on the part of the Ctcf
CKO mice across the blocks of trials (Fig. 3C; genotype effect, $\left.{ }^{* * *} p=0.0003\right)$. Therefore, although the slower swimming velocities of the Ctcf CKO mice confirmed the results from the sensorimotor battery showing possible fine motor coordination deficits, the results suggest that this functional disturbance had minimal effects on the cued learning of the $C t c f$ CKO group as indexed by the path length variable.

Analysis of the data from the place trials showed robust acquisition deficits (Fig. 3D) in the CtcfCKO mice compared with the control group in terms of path length, (Fig. 3D; genotype effect: $\left.{ }^{* *} p=0.0009\right)$, with the greatest differences occurring during blocks 4 and 5 ( $p=0.0004$ and $p<0.0005$, respectively). Importantly, the control group showed a significant decrease in path length across blocks of trials (Fig. 3D; block 1 vs block 5: $\$ p=$ 
Table 3. Results of repeated-measures ANOVA on Morris water maze data from Ctcf CKO mice and controls

\begin{tabular}{|c|c|c|c|c|}
\hline Comparison & $\begin{array}{l}\text { df (numerator; } \\
\text { denominator) }\end{array}$ & F-ratio & $p$-value & Significance \\
\hline \multicolumn{5}{|c|}{ Cued trials: escape path length } \\
\hline Genotype & $1 ; 17$ & 1.45 & 0.244 & NS \\
\hline Blocks & $3 ; 51$ & 37.7 & $<0.00005$ & $* * * *$ \\
\hline Genotype $\times$ blocks & $3 ; 51$ & 3.42 & 0.029 & * \\
\hline \multicolumn{5}{|l|}{ Cued trials: escape latency } \\
\hline Genotype & $1 ; 17$ & 11.1 & 0.004 & ** \\
\hline Blocks & $3 ; 51$ & 41.4 & $<0.00005$ & $* * * *$ \\
\hline Genotype $\times$ blocks & $3 ; 51$ & 2.3 & 0.097 & NS \\
\hline \multicolumn{5}{|l|}{ Cued trials: swim velocity } \\
\hline Genotype & $1 ; 17$ & 20.8 & 0.0003 & $* * *$ \\
\hline Blocks & $3 ; 51$ & 3.69 & 0.025 & * \\
\hline Genotype $\times$ blocks & $3 ; 51$ & 2.91 & 0.055 & NS \\
\hline \multicolumn{5}{|c|}{ Place trials: escape path length } \\
\hline Genotype & $1 ; 17$ & 16.2 & 0.0009 & $* * *$ \\
\hline Blocks & $4 ; 68$ & 4.53 & 0.005 & $* *$ \\
\hline Genotype $\times$ blocks & $4 ; 68$ & 2.58 & 0.055 & NS \\
\hline \multicolumn{5}{|l|}{ Place trials: escape latency } \\
\hline Genotype & $1 ; 17$ & 15.8 & 0.001 & $* *$ \\
\hline Blocks & $4 ; 68$ & 3.21 & 0.029 & * \\
\hline Genotype $\times$ blocks & $4 ; 68$ & 1.36 & 0.26 & NS \\
\hline \multicolumn{5}{|l|}{ Place trials: swim velocity } \\
\hline Genotype & $1 ; 17$ & 7.45 & 0.014 & * \\
\hline Blocks & $4 ; 68$ & 3.56 & 0.022 & * \\
\hline Genotype $\times$ blocks & $4 ; 68$ & 2.04 & 0.12 & NS \\
\hline
\end{tabular}

The Morris water maze was used to test spatial learning/memory in adult (3-4 months old) Ctcf CKO $(n=9)$ and control $(n=10)$ mice and repeated-measures ANOVA (rmANOVA) was performed on the data collected. The first column lists the comparison data for which the rmANOVA was performed. The second column lists the degrees of freedom (df). The third column lists the F-ratio. The fourth column lists the $p$-value. The final column indicates the degree of statistical significance.

NS, Not significant.

${ }^{*} p<0.05,{ }^{* *} p<0.01,{ }^{* * *} p<0.001,{ }^{* * * *} p<0.0001$

0.0001), whereas the CtcfCKO mice did not, but rather exhibited similar path lengths throughout acquisition training, suggesting that the control mice learned the location of the hidden platform whereas the Ctcf CKO mice failed to do so. Similar findings were observed with regard to escape latency, although differences were spuriously increased (Fig. $3 E$ ) because the Ctcf CKO group again showed significantly decreased swimming velocities compared with the control mice (Fig. $3 F$ ).

Consistent with the place learning results, the retention performance of the Ctcf CKO mice was impaired profoundly across all three dependent variables analyzed from the probe trial. Specifically, the $C t c f$ CKO group made significantly fewer platform crossings (Fig. $3 G ; t_{(17)}=4.17:{ }^{* *} p=0.0006$ ) and spent significantly less time in the target quadrant (Fig. $3 H ; t_{(17)}=3.46$ : $\left.{ }^{*} p=0.003\right)$ compared with controls. Moreover, within-subjects contrasts showed that the control group exhibited spatial bias for the target quadrant by spending significantly more time in it versus the times spent in each of the other quadrants (Fig. 3I; $\left.{ }^{* *} p<0.004\right)$, whereas the Ctcf CKO mice did not. In summary, the 3- to 4-month-old Ctcf CKO mice exhibited severe spatial learning and memory impairments to the degree that there was no evidence that any learning had occurred in these mutant mice. Although the CtcfCKO had significantly slower swimming velocities that may have affected their MWM performance, the lack of differences in path length during the cued trials suggest that the spatial learning and memory deficits were likely cognitive in nature rather than the result of nonassociative influences.

In contrast to the severe spatial learning and memory deficits exhibited by the 3- to 4-month-old Ctcf CKO mice, the adoles-
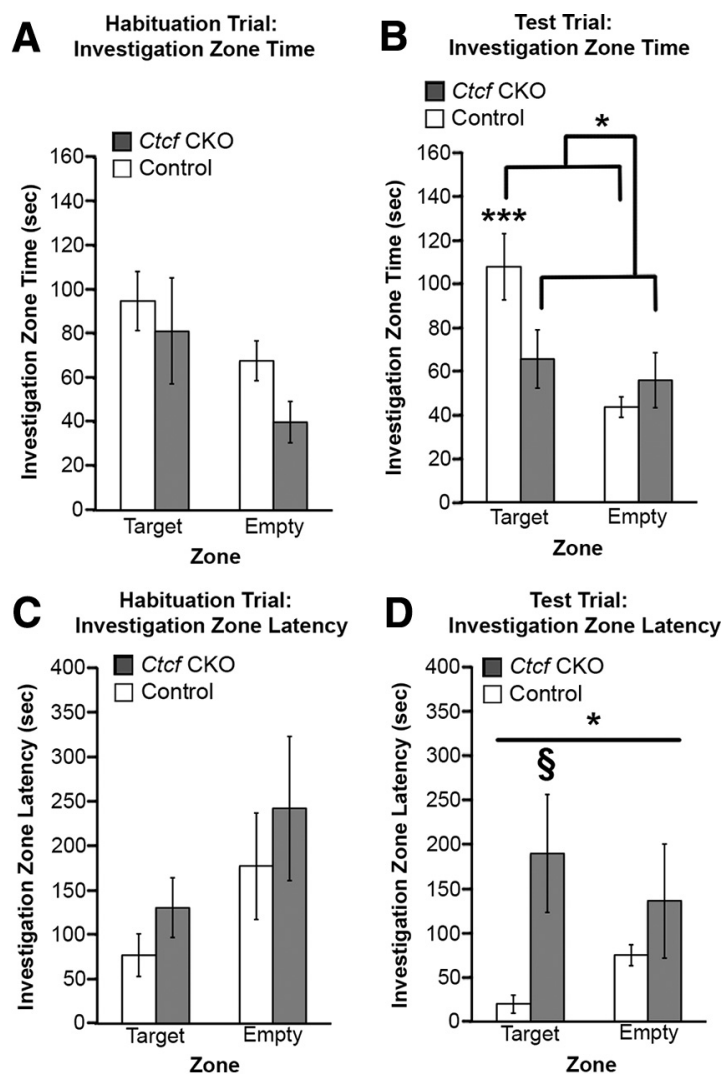

Figure 4. Adult Ctcf CKO mice exhibit decreased levels of sociability in the social approach test. Potential disturbances in sociability were assessed by quantifying investigatory behaviors during the social approach test. $\boldsymbol{A}$, During the habituation trial, both the $\operatorname{CtcfCKO}(n=9)$ and control mice $(n=10)$ tended to explore the target zone surrounding the withholding cage that would later contain the stimulus mouse compared with the withholding cage that would remain empty during the test trial, but statistical analysis of the data yielded no significant effects involving genotype. $\boldsymbol{B}$, In the test trial, control mice, but not Ctcf CKO mice, spent more time exploring the target investigation zone surrounding the withholding cage containing the stimulus mouse and less time exploring the zone surrounding the empty withholding cage. This was documented by a significant genotype $\times$ zone interaction $\left({ }^{*} p=0.020\right)$ and planned comparisons showing that the control mice spent significantly more time in the investigation zones surrounding the stimulus mouse compared with the one surrounding the empty withholding cage $\left({ }^{* * *} p=0.0004\right)$, whereas the Ctcf CKO group showed no differences in zone times. C, During habituation, latencies to enter both investigation zones were similar between genotypes. D, However, during the test trial, Ctcf CKO mice had significantly longer latencies, on average, to enter the two investigation zones surrounding the withholding cages (genotype effect: ${ }^{*} p=0.027$ ). This effect was primarily due to increased zone latencies in the Ctcf CKO mice compared with controls for the target zone around the stimulus mouse withholding cage $(\S p=0.017)$. Data are shown as means \pm SEM.

cent $C t c f C K O$ mice did not show convincing evidence of impairments during MWM testing relative to the control group (Table 1). Specifically, no significant effects involving genotype were found for any of the MWM variables with the exception of escape latency during the place condition $\left({ }^{\star} p=0.032\right.$; Table 1$)$. However, no significant differences were observed for the path length data during the place trials and no differences were found for any of the probe trials variables, suggesting that the escape latency findings may have been affected by differences in swimming speeds.

We assessed Ctcf CKO mice for potential deficits in sociability by quantifying investigatory behaviors during the social approach test (Dougherty et al., 2013; Silverman et al., 2011; Moy et al., 2004). During habituation, in which no conspecific (stimulus mouse) was present, both Ctcf CKO and control mice tended to 

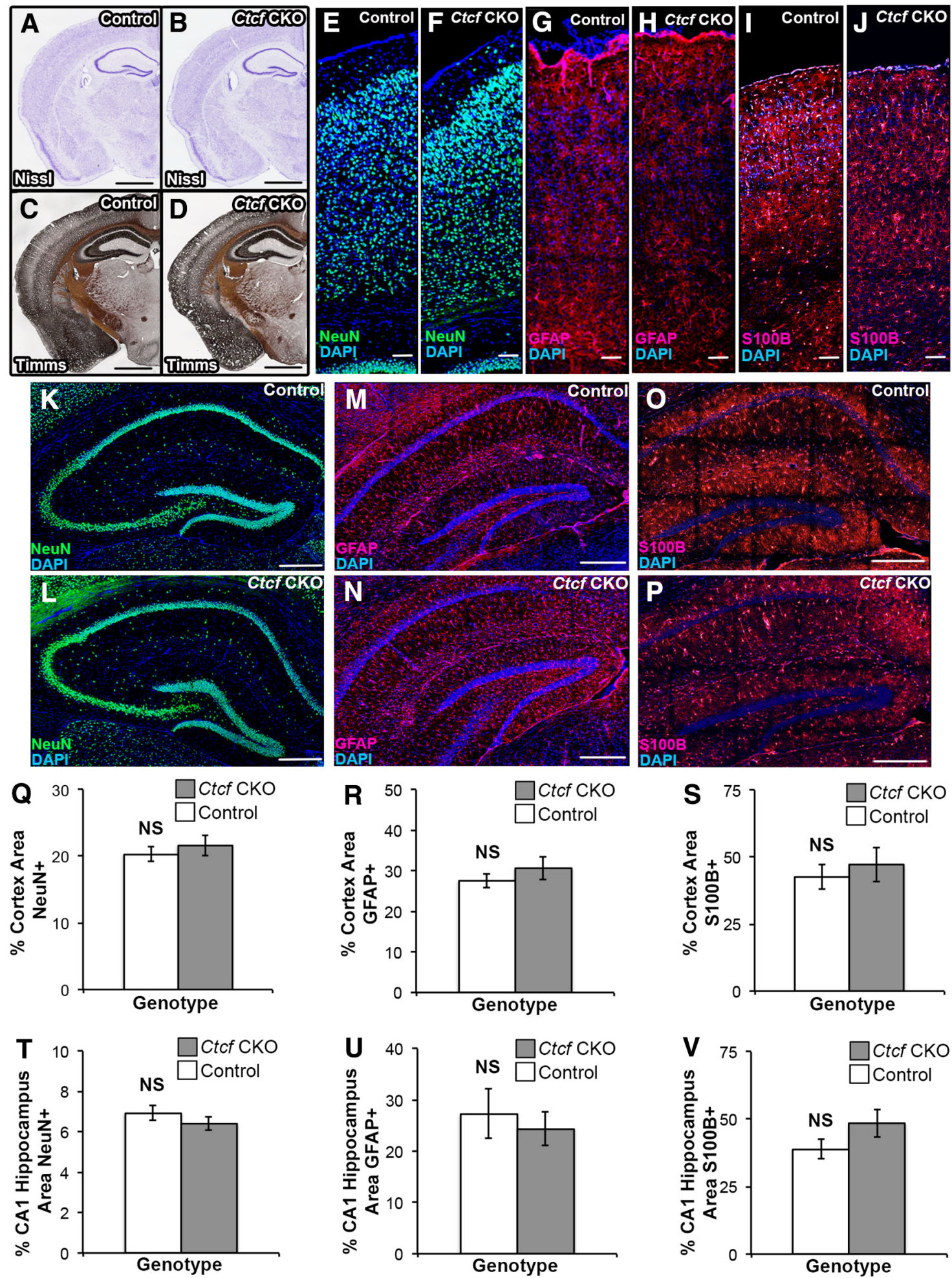

Figure 5. Brain neuroanatomy of Ctcf CKO mice is grossly normal. $\boldsymbol{A}, \boldsymbol{B}$, Nissl (cresyl violet) staining of brain from control animals $(\boldsymbol{A})$ and $C t c f$ CKO animals $(\boldsymbol{B})$ demonstrating typical neuroanatomic structures in mice of both genotypes. $\boldsymbol{C}, \boldsymbol{D}$, Timm's silver sulfide staining of brain from control animals $(\boldsymbol{C})$ and $C t c f C K 0$ animals $(\boldsymbol{D})$ was also similar. $\boldsymbol{E}, \boldsymbol{F}$, NeuN staining for neurons was similar in the cerebral cortex of control animals $(\boldsymbol{E})$ and $(\boldsymbol{C t} f \mathrm{CKO}$ animals $(\boldsymbol{F}$; quantitated in $\boldsymbol{Q}) . \mathbf{G}, \boldsymbol{H}$, GFAP staining for astrocytes was similar in the cerebral cortex of control animals $(\boldsymbol{G})$ and $C t c f$ CKO animals ( $\boldsymbol{H}$; quantitated in $\boldsymbol{R}) . \boldsymbol{I}, \boldsymbol{J}$, Staining for the astrocyte marker S100B was also similar in the cortex of control animals $(\boldsymbol{I})$ and $(t c f C K 0$ mice $(\boldsymbol{J}$; quantitated in $\boldsymbol{S})$. $\boldsymbol{K}$ I In CA1 hippocampus, NeuN staining was similar between control and $(\boldsymbol{L}) \boldsymbol{C t c f C K 0}$ animals (quantitated in $\boldsymbol{T}) . \boldsymbol{M}, \boldsymbol{N}, \mathrm{GFAP}$ staining in CA1 hippocampus was similar between control animals $(\boldsymbol{M})$ and $(t \in f C K 0$ mice $(\boldsymbol{N}$; quantitated in $\boldsymbol{U}) . \mathbf{O}, \boldsymbol{P}, S 100 B$ staining in $C A 1$ hippocampus also was similar between control animals $(\boldsymbol{O})$ and $\mathrm{Ctcf} C \mathrm{CK} 0$ animals $(\boldsymbol{P}$; quantitated in $\boldsymbol{V})$. Images in $\boldsymbol{E}-\boldsymbol{P}$ are counterstained with the nuclear indicator DAPI. Scale bars: $\boldsymbol{A}-\boldsymbol{D}, 1 \mathrm{~mm} ; \boldsymbol{E}-\boldsymbol{J}, 75 \mu \mathrm{m} ; \boldsymbol{K}-\boldsymbol{P}, 300 \mu \mathrm{m}$. In $\mathbf{Q} \boldsymbol{-} \boldsymbol{V}$, we quantified the percentage area of CA1 hippocampus and cortex stained with each antibody ( $n=$ images from at least 3 animals per genotype). All quantitative comparisons were nonsignificant (NS) as follows: NeuN cortex ( $n=24$ images/genotype, $t$ test: $\left.t_{(46)}=0.6865 ; p=0.4958 ; \mathbf{Q}\right) ;$ GFAP cortex ( $n=12$ images/ genotype, $t$ test: $\left.t_{(22)}=0.9306 ; p=0.3621 ; R\right) ; S 100 B$ cortex $(n=8$ images/genotype, Mann-Whitney $U=18, p=0.1605 ; S)$; NeuN CA1 hippocampus $(n=13$ CKO and 12 control images, $t$ test: $\left.t_{(23)}=1.08, p=0.2912 ; T\right) ;$ GFAP CA1 hippocampus ( $n=12$ images/genotype, $t$ test: $\left.t_{(22)}=0.5123, p=0.6136 ; \boldsymbol{U}\right)$; and S100B CA1 hippocampus ( $n=6$ CK0 and 7 control images, Mann-Whitney $U=15, p=0.4452 ; \boldsymbol{V})$. Therefore, we found the density of neurons and astrocytes in the brains of CtcfCKO and control mice to be similar. Data are shown as means \pm SEM. 

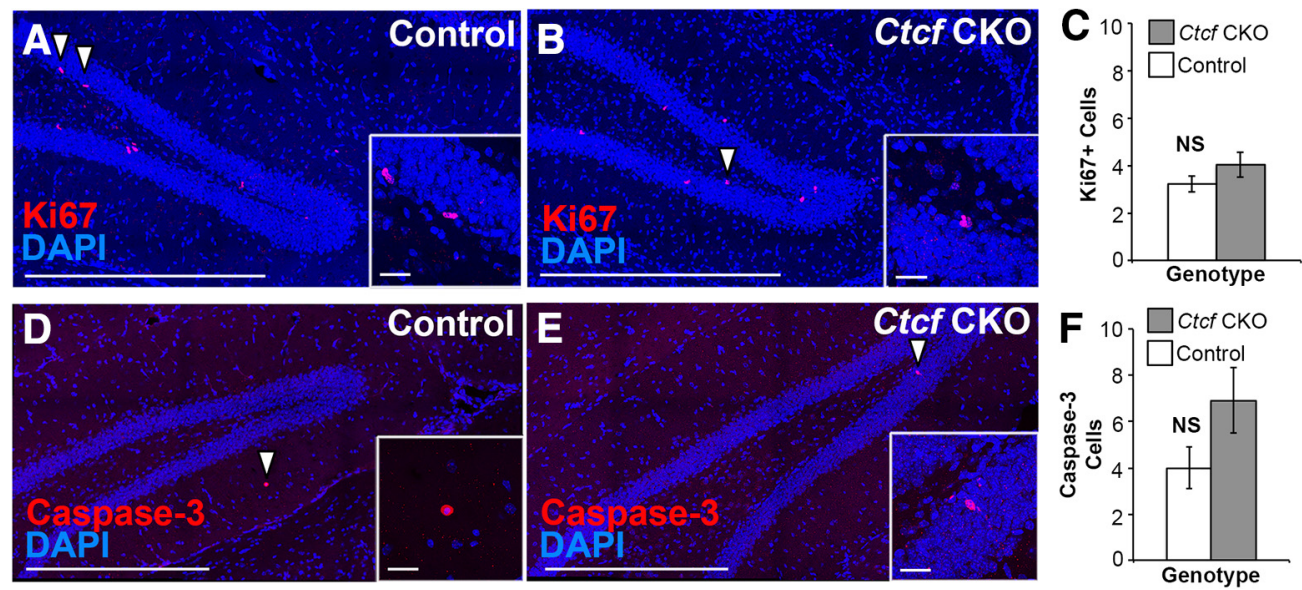

Figure 6. CtcfCKO mice have normal levels of cell birth and cell death. $\boldsymbol{A}, \boldsymbol{B}$, Immunostaining for Ki67, an antigen marker of proliferating cells, in control $(\boldsymbol{A})$ and $(\mathrm{Ct} f \mathrm{CKO}(\boldsymbol{B})$ mouse dentate gyrus. C, Quantification of Ki67 ${ }^{+}$cells based on manual counting of 40- $\mu \mathrm{m}$-thick brain sections. Most positive cells were present in the dentate gyrus in both groups $(n=63$ control sections, $n=53$ Ctcf CKO sections, Mann-Whitney $U=1465, p=0.2547) . \boldsymbol{D}, \boldsymbol{E}$, Immunostaining for cleaved caspase-3, an antigen marker of apoptotic cells, in control (D) and (tcfCKO (E) mouse dentate gyrus. Positive cells were rare. Dentate gyrus is shown for comparison with Ki67 above. $\boldsymbol{F}$, Quantification of cleaved caspase- $3^{+}$cells based on manual counting of $40-\mu \mathrm{m}$-thick brain sections $(n=12$ sections/genotype, $t$ test: $\left.t_{(22)}=1.749, p=0.0942\right)$. Main panel images were taken at $20 \times$ magnification. Scale bars, $500 \mu \mathrm{m}$. Arrowheads indicate areas of interest depicted in inset images. Insets were taken at $63 \times$ magnification. Scale bars, $25 \mu \mathrm{m}$. NS, Not significant. Data are shown as means \pm SEM.

explore the target zone surrounding the withholding cage that would later contain the stimulus mouse compared with the withholding cage that would remain empty, but analysis of the data did not yield any significant effects involving genotype (Fig. 4A). However, when a stimulus mouse was introduced into the target withholding cage for the test trial, only controls preferred to investigate it (Fig. $4 B)$. This was documented by a significant genotype $\times$ zone interaction effect (Fig. $4 B$; $\left.F_{(1,17)}=6.55,{ }^{\star} p=0.020\right)$, followed by planned within-subjects comparisons showing that the control mice spent significantly more time in the investigation zones surrounding the stimulus mouse compared with the one surrounding the empty withholding cage (Fig. $4 B ;{ }^{* *} p=$ 0.0004), whereas the Ctcf CKO group showed no differences in zone times. Latencies to enter both investigation zones were similar during habituation (Fig. 4C), but, during the test trial (Fig. 4D), Ctcf CKO mice had significantly longer latencies, on average, to enter the two investigation zones (Fig. $4 D$; genotype effect: $\left.F_{(1,17)}=5.82,{ }^{*} p=0.027\right)$. This effect was mostly due to significantly increased zone latencies in the Ctcf CKO mice compared with the control group for the target zone around the stimulus mouse, (Fig. $4 D ; F_{(1,17)}=$ $7.04, \$ p=0.017)$. Therefore, although there were no significant genotype effects concerning the test trial variables, the results of planned comparison suggested that 3- to 4 month-old Ctcf CKO mice exhibit reduced levels of social interaction with a conspecific, possibly indicating abnormally low levels of sociability.

Hippocampal seizures impair spatial learning and sociability in rodents (Gilbert et al., 2000; Krishnan et al., 2017). Therefore, we performed EEG recording of adult Ctcf CKO and control mice ( $n=6$ per genotype, 6 weeks of continuous monitoring per ani-

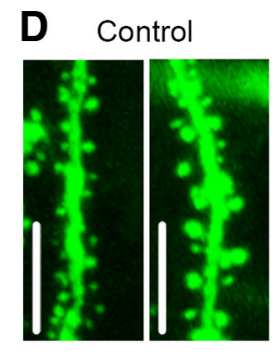

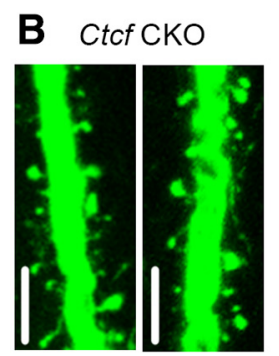
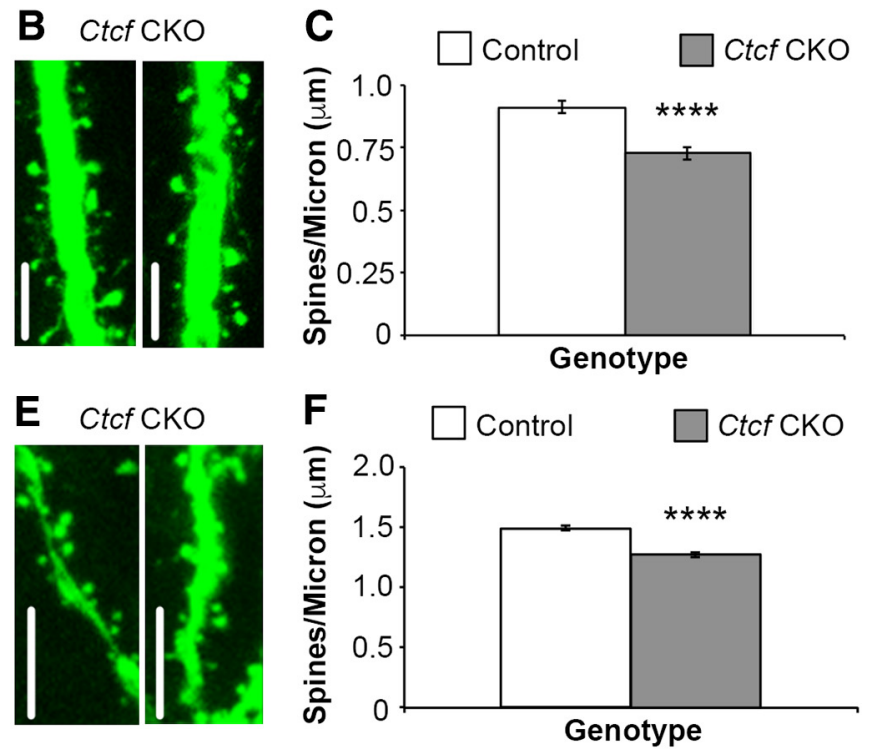

Figure 7. $\quad C t c f(K 0$ mice have decreased dendritic spine density in CA1 hippocampus and cerebral cortex. Individual proximal dendrites from adult ( 3 months old) control and CtcfCKO mice carrying a Thy T-YFP allele were imaged with a confocal microscope. The number of dendritic spines ( $n=3$ animals/genoype, 50 dendrites/animal for hippocampus, $28-32$ dendrites/animal for cortex) in each image was quantified. Representative dendrites from layer $V$ of the cerebral cortex of control $(\boldsymbol{A})$ and $(\mathrm{Ct} f \mathrm{CKO}(\boldsymbol{B})$ mice are displayed. C, CtcfCKO mice had fewer spines per micron than controls in the cerebral cortex (20\% reduction, $t$ test: $t_{(179)}=$ $\left.5.533,{ }^{* * * *} p<0.0001\right)$. Representative dendrites from the CA1 hippocampus of control (D) and (tcfCKO (E) mice are displayed. $F$, Ctcf CKO mice also had fewer spines per micron than controls in the CA1 hippocampus (15\% reduction, $t$ test: $t_{(298)}=6.731$, $\left.{ }_{* * * *} p<0.0001\right)$. Data are shown as means \pm SEM.

mal) to screen for seizure activity. No seizures were detected in Ctcf CKO mice (data not shown).

After our behavioral phenotyping of Ctcf CKO mice, we performed detailed histological analyses of their brains. We used adult mice that were 3-4 months old, the same age at which we identified behavioral abnormalities. Nissl staining of neuronal cell bodies was similar between Ctcf CKO mice and controls, indicating that gross neuroanatomical structures were preserved in Ctcf CKO mice (Fig. 5A,B). The pattern of Timm silver sulfide staining (Danscher and Zimmer, 1978) was similar between Ctcf $\mathrm{CKO}$ and control mice (Fig. $5 C, D$ ), indicating that the overall 


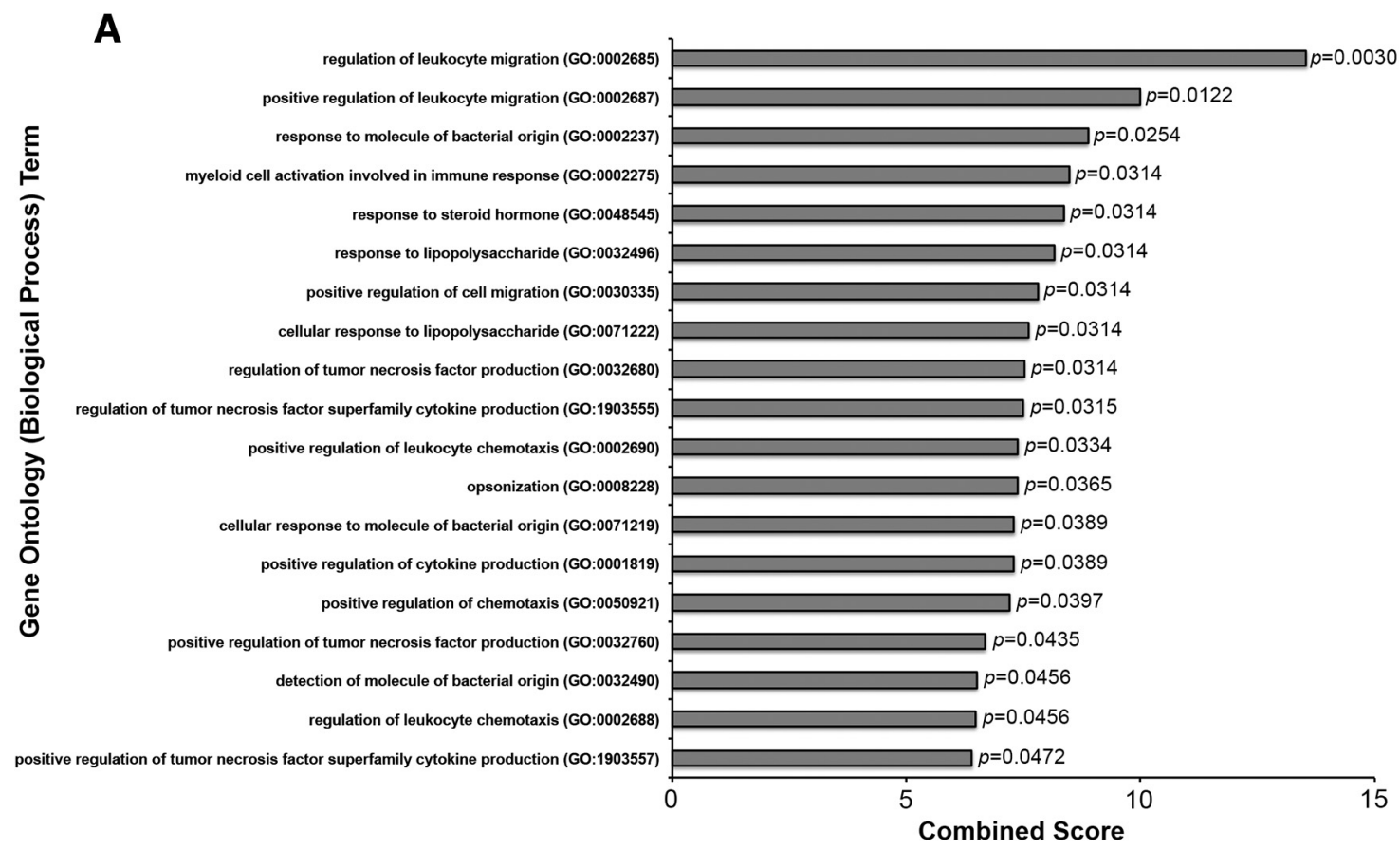

B qRT-PCR of Inflammation-Related Gene Transcription in Whole Hippocampus

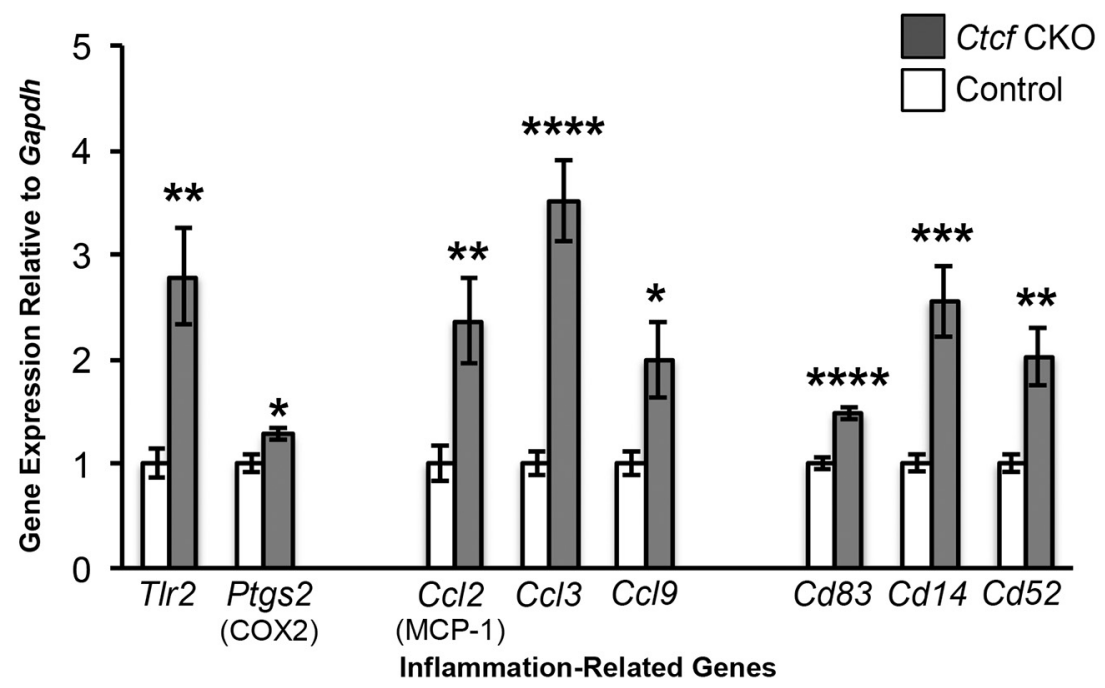

Figure 8. CtcfCKO mice have increased expression of inflammation-related genes in the hippocampus. mRNA was isolated from the hippocampus of control and $C t c f C K 0$ mice and hybridized to Agilent Technologies 4x44k v2 mouse microarrays ( $n=3$ samples/genotype, see methods for details). $\boldsymbol{A}$, Enrichr analysis of upregulated genes from Ctcf CKO mouse hippocampus identified enrichment for 19 gene ontology (biological process) terms related to inflammation. Each bar is labeled with its computed Benjamini-Hochberg adjusted $p$-value and the bar length corresponds to the magnitude of the Enrichr combined score. B, qRT-PCR for inflammation-related genes on hippocampal mRNA ( $n=8$ samples/genotype) confirmed significant upregulation of genes T/r2 (2.8-fold upregulated, $t$ test: $t_{(14)}=3.762,{ }^{* *} p=0.0021$ ), Ptgs2 (encoding COX2; 1.3-fold upregulated, $t$ test: $t_{(14)}=2.57,{ }^{*} p=0.0222$ ), C(I2 (encoding MCP-1; 2.4-fold upregulated, $t$ test: $\left.t_{(14)}=3.033{ }^{* *} p=0.0089\right)$, Ccl3 (3.5-fold upregulated, $t$ test: $\left.t_{(14)}=6.259,{ }^{* * * *} p<0.0001\right)$, Ccl9 (2.0-fold upregulated, $t$ test: $\left.t_{(14)}=2.634,{ }^{*} p=0.0196\right)$, Cd83 (1.5-fold upregulated, $t$ test: $\left.t_{(14)}=5.378,{ }^{* * * *} p<0.0001\right)$, Cd14 (2.6-fold upregulated, $t$ test: $\left.t_{(14)}=4.461,{ }^{* * *} p=0.0005\right)$, and (d52 (2-fold upregulated, $t$ test: $\left.t_{(14)}=3.545,{ }^{* *} p=0.0032\right)$. Data are shown as means \pm SEM.

anatomy of synaptic vesicle-containing nerve fiber tracts was preserved. We performed immunostaining on brain sections from Ctcf CKO and control mice ( $n=3$ mice/genotype) and evaluated cerebral cortex for the neuron-specific antigen NeuN (Fig. 5 E, F; $n=24$ images/genotype) and the astrocyte antigens GFAP (Fig. $5 \mathrm{G}, \mathrm{H} ; n=12$ images/genotype) and S100B (Fig. 5I,J; $n=8$ images/genotype). We quantified the percentage area of each section stained by each antibody and found no significant differences between genotypes (Fig. 5Q-S; NeuN: $t$ test, $t_{(46)}=0.6865$, $p=0.4958$; GFAP: $t$ test, $t_{(22)}=0.9306 ; p=0.3621$; and S100B: Mann-Whitney $U=18, p=0.1605)$. Similarly, we evaluated CA1 hippocampus from sections immunostained for NeuN (Fig. $5 \mathrm{~K}, L ; n=13 \mathrm{CKO}$ and 12 control images), GFAP (Fig. $5 \mathrm{M}, \mathrm{N}$; $n=12$ images/genotype), and S100B (Fig. 5O,P; $n=6$ CKO and 7 control images). Again, quantification of the area stained by each antibody revealed no differences between genotypes (Fig. $5 T-V$; NeuN: $t$ test, $t_{(23)}=1.08, p=0.2912$; GFAP: $t$ test, $t_{(22)}=$ $0.5123, p=0.6136$; and S100B: Mann-Whitney $U=15, p=$ 
0.4452). Overall, we found that Ctcf CKO and control mouse brains have similar structural features, including equivalent complements of neurons and astrocytes.

We also evaluated cell turnover in $\operatorname{CtcfCKO}$ and control mice ( $n=3$ mice/genotype) by immunostaining for Ki67, a marker of dividing cells (Fig. $6 A, B ; n=63$ control sections, $n=53$ Ctcf CKO sections), and cleaved caspase-3, a marker of cell death (Fig. $6 D, E ; n=12$ sections/genotype). There were no significant differences between $C t c f$ CKO mice and controls with regard to either the number of $\mathrm{Ki}^{+} 7^{+}$cells/section (Fig. 6C; Mann-Whitney $U=1465, p=0.2547$ ) or the number of cleaved caspase- $3^{+}$ cells/section (Fig. $6 F$; $t$ test: $t_{(22)}=1.749, p=0.0942$ ). In summary, cell turnover was similar between Ctcf CKO and control mice.

Dendritic spines are the anatomic structures where most synapses occur on gluatamatergic neurons (Alvarez and Sabatini, 2007). Decreased dendritic spine number is observed in animal models of neurodevelopmental disorders including ASD and intellectual disability (Martínez-Cerdeño, 2017). Ctcf;Nex-Cre conditional $\mathrm{KO}$ mice have decreased spine number (Hirayama et al., 2012) and we suspected that Ctcf CKO mice harbored a similar abnormality given their behavioral phenotype. To evaluate dendritic spines in Ctcf CKO mice, we intercrossed them with mice carrying a Thyl-YFP transgene and visualized microscopically brain sections from Ctcf CKO;Thy1-YFP mice and controls carrying the $C t c f^{\text {loxP }}$ and Thy1-YFP alleles in the absence of Cre. Compared with controls, Ctcf $\mathrm{CKO}$ mice had a significant reduction in dendritic spine density in both layer $\mathrm{V}$ of the cerebral cortex (Fig. $7 A-C$; $t$ test, $\left.t_{(179)}=5.533,{ }^{* * *} p<0.0001\right)$ and CA1 hippocampus (Fig. $7 D-F$; $t$ test, $t_{(298)}=6.731^{\star * * *} p<0.0001$ ), the two regions where Camk2a-Cre is primarily expressed. Therefore, $C t c f \mathrm{CKO}$ mice have decreased numbers of dendritic spines in brain regions deficient for CTCF, similar to Ctcf;Nex-Cre conditional $\mathrm{KO}$ mice and reminiscent of neuropathologic changes observed in human disorders linked to cognitive dysfunction.

We went on to characterize gene expression in Ctcf CKO mouse hippocampus by performing microarray analysis of mRNA isolated from pooled tissue from Ctcf CKO mice and controls $(n=3$ samples/genotype). We identified 367 upregulated genes and 148 downregulated genes $(p<0.05$, fold change $> \pm 1.5)$ in CtcfCKO hippocampus, including Ctcf. We used the EnrichR bioinformatics tool (Chen et al., 2013) to explore gene ontology-biological process (GO-BP) terms enriched in our list of upregulated genes (Fig. 8A). Suprisingly, most of the significant terms that we identified ( $45 \%$ or $19 / 42$ ) were related to inflammation, including the overall second-ranked term, regulation of leukocyte migration (GO:0002685; $p=0.0030$ ).

We used qRT-PCR to independently confirm overexpression of inflammation-related genes identified by our bioinformatics analysis (Fig. $8 B$ ), including: Tlr2, encoding toll-like receptor 2, which activates brain microglia $\left(t\right.$ test, $t_{(14)}=3.762,{ }^{* *} p=0.0021$; Hayward and Lee, 2014), and Ptgs2, encoding prostaglandin-endoperoxide synthase $2 / \mathrm{COX} 2$, which synthesizes inflammatory prostaglandins ( $t$ test, $t_{(14)}=2.57,{ }^{\star} p=0.0222$; Minghetti, 2004). We also confirmed overexpression of genes encoding secreted inflammatory proteins called chemokines (Miller et al., 2008), including: $\mathrm{Ccl}$, encoding $\mathrm{C}-\mathrm{C}$ motif chemokine ligand 2/MCP-1 $\left(t\right.$ test, $\left.t_{(14)}=3.033{ }^{* *} p=0.0089\right)$; Ccl3, encoding $\mathrm{C}-\mathrm{C}$ motif chemokine ligand 3 ( $t$ test, $\left.t_{(14)}=6.259,{ }^{* * * *} p<0.0001\right)$; and $C c 19$, encoding C-C motif chemokine ligand 9 ( $t$ test, $t_{(14)}=$ $\left.2.634,{ }^{\star} p=0.0196\right)$. We further confirmed overexpression of microglia markers, including: Cd83, encoding CD83 antigen $\left(t\right.$ test, $t_{(14)}=5.378,{ }^{* * *} p<0.0001$; Fujimoto and Tedder, 2006);

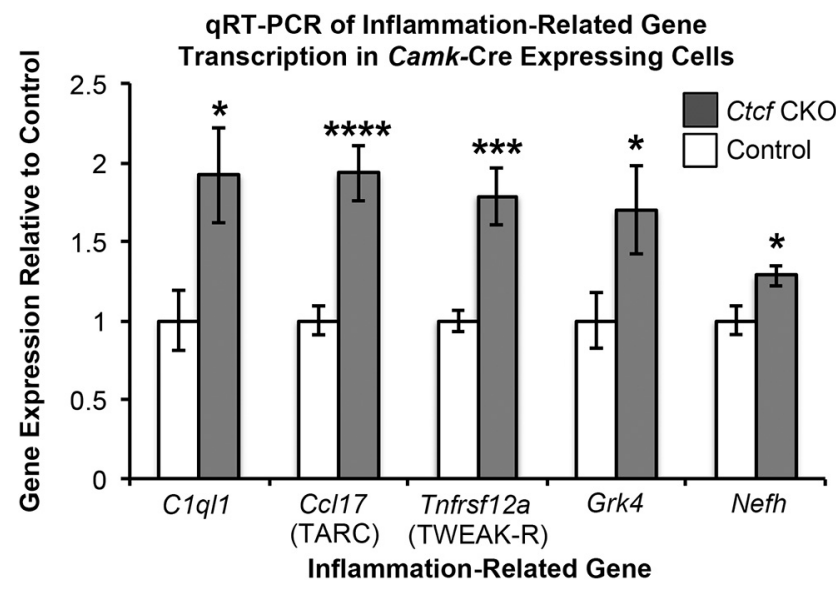

Figure 9. Hippocampal Camk2a-Cre-expressing neurons lacking Ctcf overexpress immunomodulatory genes. RiboTag-isolated mRNA from Camk2a-Cre-expressing hippocampal cells in control;RiboTag and (tcf CKO;RiboTag mice ( $n=4$ samples/genotype) was hybridized to Agilent Technologies $8 \times 60 \mathrm{k}$ mouse microarrays. We confirmed overexpression of select genes by qRT-PCR on RiboTag-isolated mRNA ( $n=12$ samples/genotype), including (1q/1 (1.9-fold upregulated, $t$ test: $t_{(22)}=2.563,{ }^{*} p=0.0177$ ), , cl17 (encoding TARC; 1.9 -fold upregulated, $t$ test: $t_{(22)}=4.759,{ }^{* * * *} p<0.0001$ ), Infrsf12a (encoding FN14/TWEAK-R; 1.8 -fold upregulated, $t$ test: $\left.t_{(22)}=4.025,{ }^{* * *} p=0.0006\right)$, Grk4 (1.7-fold upreglated, $t$ test: $t_{(22)}=2.119$, $\left.{ }^{*} p=0.0457\right)$, and Nefh (1.3-fold uprelated, $t$ test: $\left.t_{(22)}=2.548,{ }^{*} p=0.0183\right)$. Data are shown as means \pm SEM.

$C d 14$, encoding CD14 antigen $\left(t\right.$ test, $t_{(14)}=4.461,{ }^{* * *} p=$ 0.0005; Becher et al., 1996); and Cd52, encoding CD52 antigen $(t$ test, $t_{(14)}=3.545,{ }^{\star *} p=0.0032$; Chatterjee et al., 2014). The enrichment of inflammation-related genes in CtcfCKO mouse hippocampus suggested to us that immune dysfunction might contribute to the phenotype of these animals given the role of inflammation in neurodevelopmental disorders such as ASD (Estes and McAllister, 2015).

Next, we sought to assess the transcriptional profile of Camk2aexpressing cells to distinguish altered gene expression specific to Ctcf-deficient neurons from secondary changes in non-neuronal cells. To this end, we intercrossed Ctcf CKO and RiboTag mice (Sanz et al., 2009), which express a hemagglutinin-tagged version of ribosomal protein Rpl22 in cells expressing Cre-recombinase. We performed affinity purification of HA-tagged ribosomes and associated mRNA from Camk2a-Cre expressing cells in the hippocampus of CtcfCKO;RiboTag and Camk2a-Cre;RiboTag control mice ( $n=4$ individual animals per genotype) and analyzed differential gene expression by microarray. We identified 312 upregulated and 167 downregulated genes $(p<0.05$, fold change $> \pm 1.5$ ). We analyzed the list of upregulated genes to identify ones capable of triggering increased expression of inflammationrelated genes, such as those observed in whole hippocampus. We used qRT-PCR to independently confirm overexpression of four such genes in Ctcf CKO;RiboTag samples (Fig. 9), including: C1ql1, encoding complement C1q-like 1, a neuronally expressed complement protein involved in activity-dependent synapse formation ( $t$ test, $t_{(22)}=2.563,{ }^{\star} p=0.0177$; Yuzaki, 2017); Ccl17, encoding C-C motif chemokine ligand 17 (also known as thymus- and activation-regulated chemokine, or TARC), a neuronally expressed chemokine $\left(t\right.$ test, $t_{(22)}=4.759,{ }^{* * * *} p<$ 0.0001; Henry et al., 2015); Tnfrsf12a, encoding TNF receptor superfamily member 12A (also known as fibroblast growth factor-inducible 14, FN14, or TNF-related weak inducer of apoptosis receptor, TWEAK-R), a receptor for microglia-produced cytokines ( $t$ test, $t_{(22)}=4.025,{ }^{* *} p=0.0006$; Winkles, 2008); and 
A
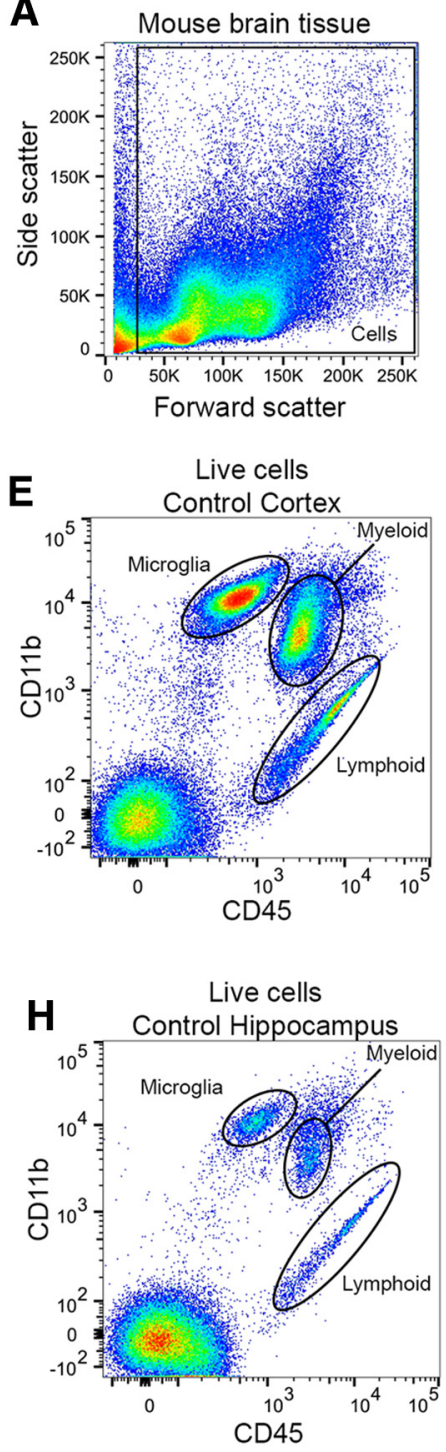

B
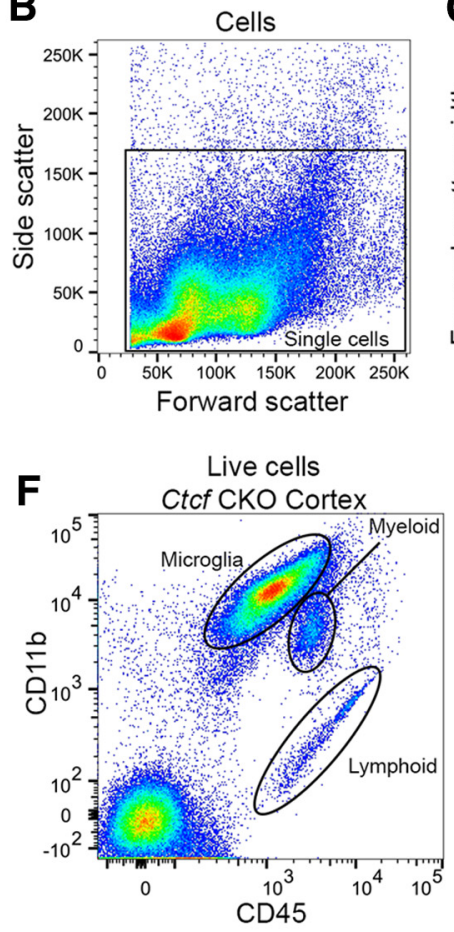

Live cells

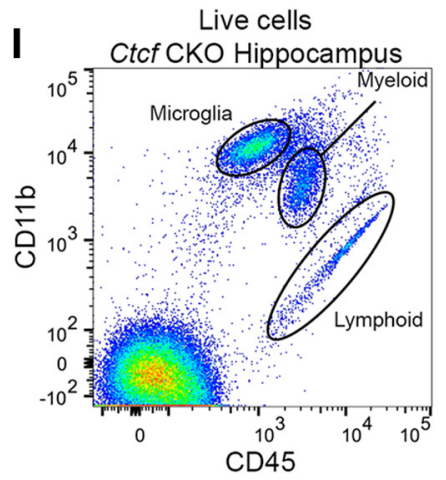

C

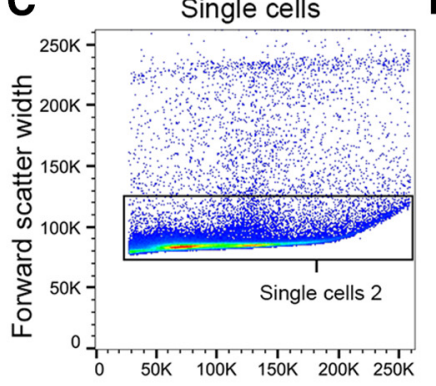

Forward scatter
D

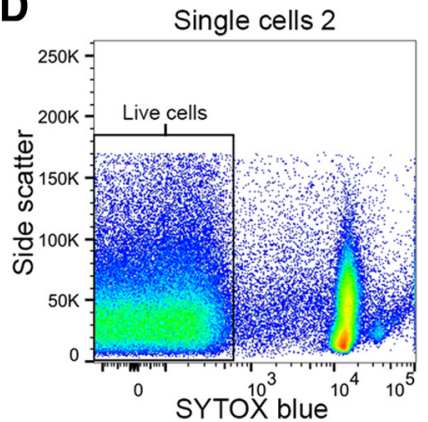

Cortex
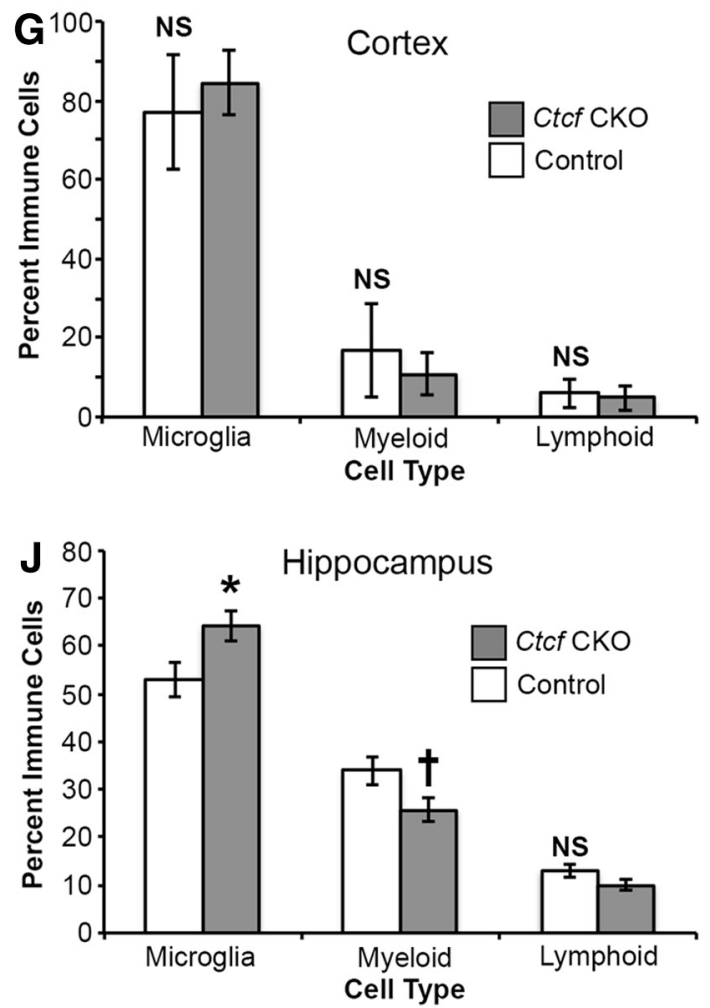

Figure 10. Flow cytometry revealing an increased proportion of CD11b high, CD45 intermediate microglia in the hippocampus of CtcfCKO mice. Flow cytometry was performed on CtcfCK0 and control mouse hippocampus ( $n=14 /$ genotype). $\boldsymbol{A}-\boldsymbol{C}$, Whole hippocampus and cerebral cortex cell suspensions $(\boldsymbol{A})$ were gated for cells $(\boldsymbol{B})$, which in turn were gated for single cells $(\boldsymbol{C})$. $\boldsymbol{D}$, SYTOX blue-negative, live cells were selected and sorted according to CD11b and CD45 status as shown in $\boldsymbol{E}, \boldsymbol{F}, \boldsymbol{H}$, and $\boldsymbol{I}$. Populations of CD11b-high, CD45-intermediate microglia, CD11b-high, CD45-high myeloid cells, and CD11b-low, CD45-high lymphoid cells were discernible. $\boldsymbol{E}$, Compared with control cortex samples, $(\boldsymbol{F})$ CtcfCKO cortex samples had similar proportions of microglia (quantified in G), $t$ test: $t_{(27)}=1.61, p=0.1189$ ), myeloid cells ( $t$ test: $\left.t_{(27)}=1.72, p=0.0969\right)$, and lymphoid cells ( $t$ test: $\left.t_{(27)}=0.9363, p=0.3574\right)$. NS, Not significant. $\boldsymbol{H}$, Compared with control hippocampus samples, $(I)$ Ctcf CKO hippocampus samples had a higher proportion of microglia (quantified in $J, t$ test: $t_{(27)}=2.214,{ }^{*} p=0.0355$ ) and a lower proportion of myeloid cells ( $t$ test: $\left.t_{(27)}=2.128, \dagger p=0.0426\right)$, whereas the proportion of lymphoid cells was unchanged $\left(t\right.$ test: $\left.t_{(27)}=1.671 p=0.1062\right)$. Data are shown as means \pm SEM.

Grk4, encoding G-protein-coupled receptor kinase 4 ( $t$ test, $\left.t_{(22)}=2.119,{ }^{\star} p=0.0457\right)$, a member of a family of kinases that interact with chemokine receptors (Ali et al., 2000). We also identified upregulation of Nefh, encoding neurofilament heavy polypeptide, a marker of neuronal injury $\left(t\right.$ test, $t_{(22)}=2.548,{ }^{\star} p=$ 0.0183; Gresle et al., 2008).

We compared the gene expression profiles obtained from both microarray experiments by "subtracting" the RiboTagderived Ctcf CKO-profile from the whole hippocampus Ctcf CKO profile. We observed upregulation of microglia markers (e.g., Cd14, Cd52, Cd83, Tlr2; Zhang et al., 2014) in the "non neural" component; that is, increased expression in the CtcfCKO whole hippocampus, but not in the $C t c f$ CKO RiboTag set. This suggested the presence of microglia in the hippocampus and led us to investigate the composition of inflammatory cells in the relevant brain regions of $\operatorname{Ctcf} \mathrm{CKO}$ mice.
First, we performed flow cytometry to isolate live cells from dissociated hippocampal and cerebral cortical tissues of Ctcf CKO and control mice ( $n=14$ /genotype; Fig. $10 A-D)$. We used CD45 and CD11b expression to identify inflammatory cells and sort them into three populations: microglia (CD11b high, CD45 intermediate); myeloid cells, including macrophages and neutrophils (CD11b high, CD45 high); and lymphoid cells, including B and T lymphocytes (CD11b low, CD45 high; Galatro et al., 2017). We found no effect of genotype on the proportion of cells of each lineage isolated from cerebral cortex (Figure 10E-G; microglia $t$ test: $t_{(27)}=1.61, p=0.1189$; myeloid cells $t$ test: $t_{(27)}=1.72, p=$ 0.0969 ; lymphoid cells $t$ test: $\left.t_{(27)}=0.9363, p=0.3574\right)$. However, compared with controls, (Fig. $10 H$ ) the inflammatory cells isolated from CtcfCKO hippocampus (Fig. 10I) had an increased proportion of microglia (Fig. $10 \mathrm{~J} ; t$ test, $t_{(27)}=2.214,{ }^{\star} p=$ 0.0355 ) and a decreased proportion of myeloid cells (Fig. 10J; $t$ 

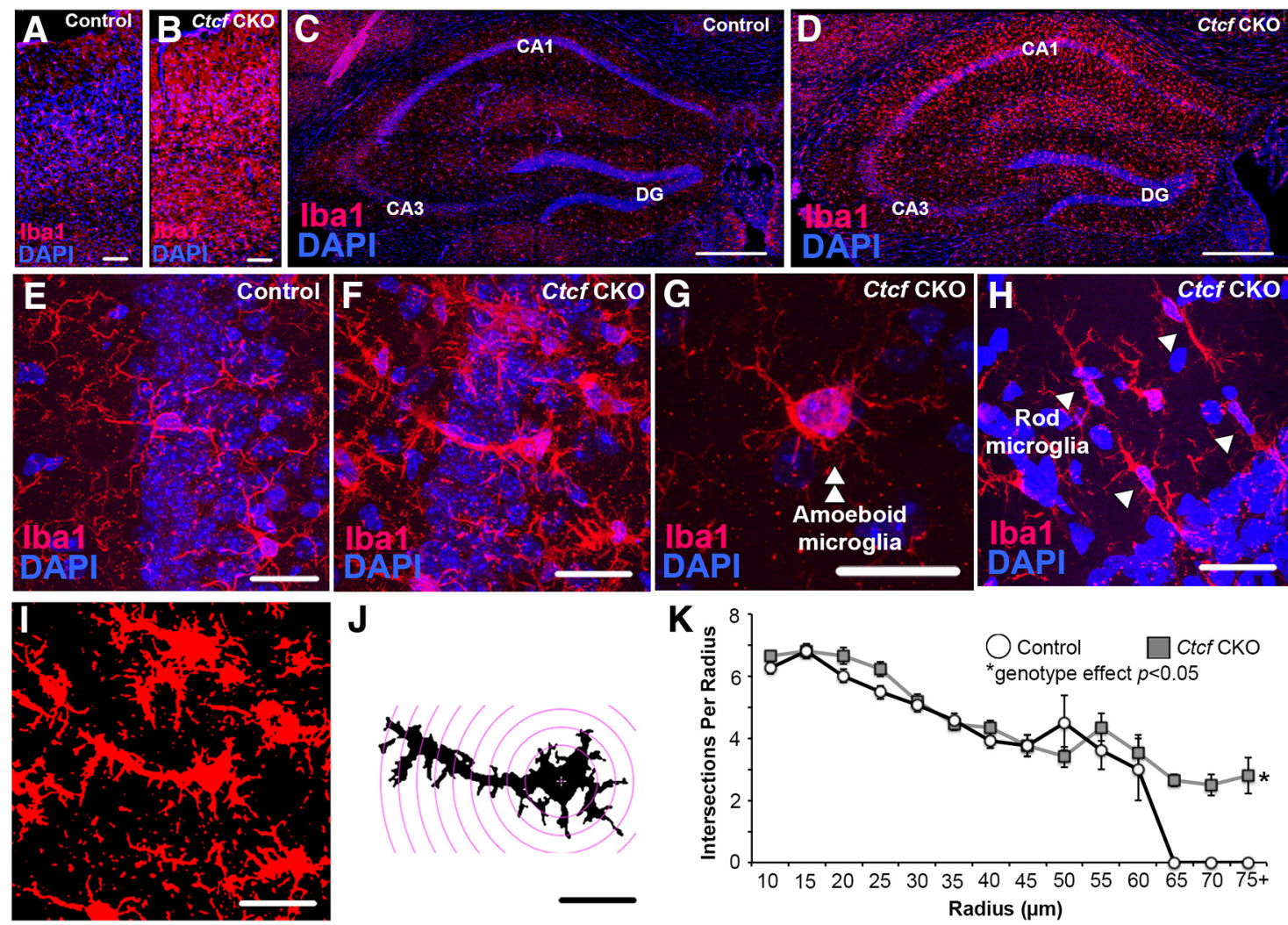

Figure 11. Hippocampal microglia in Ctcf CKO mice are morphologically abnormal. $\boldsymbol{A}-\boldsymbol{D}$, lba1 staining of control $(\boldsymbol{A})$ and $C t c f$ CKO (B) cerebral cortex and of control (C) and Ctcf CKO (D) hippocampus demonstrating increased staining for Iba1-positive microglia in CtcfCKO tissues. $\boldsymbol{E}, \boldsymbol{F}$, High-power image of anti-lba1 immunostained CA1 hippocampus from control (E) and CtcfCKO $(\boldsymbol{F})$ mice. $\mathbf{G}, \boldsymbol{H}$, Microglia with amoeboid morphology (double arrowhead; $\boldsymbol{G}$ ) and rod-shaped microglia (single arrowheads; $\boldsymbol{H}$ ) were observed in CtcfCKO mice, but not in controls. $\boldsymbol{I}$, Example of thresholded mean intensity projection of Iba1-stained image from CA1 hippocampus of the type used for Sholl analysis. J, Example of single microglial cell with concentric Sholl radii (pink circles) superimposed on the image. $\boldsymbol{K}$, Sholl analysis ( $n=6$ mice/genotype, 25 microglia per mouse) identified an overall increase in the number of process intersections per radius in microglia from the CA1 region of CtcfCKO mice (rmANOVA, genotype effect: $F_{(1,298)}=4.549,{ }^{*} p=0.0338$ ). Note that only microglia from CtcfCKO mice had processes that extended $\geq 65 \mu \mathrm{m}$ from the soma. Scale bars: $\boldsymbol{A}, \boldsymbol{B}, 75 \mu \mathrm{m} ; \boldsymbol{C}, \boldsymbol{D}, 375 \mu \mathrm{m} ; \boldsymbol{E}-\boldsymbol{J}, 25 \mu \mathrm{m}$. Graph in $\boldsymbol{K}$ shows means \pm SEM.

test, $\left.t_{(27)}=2.128, \dagger p=0.0426\right)$; the proportion of lymphoid cells in the hippocampus was similar between genotypes (Fig. 10J; $t$ test, $\left.t_{(27)}=1.671, p=0.1062\right)$.

Next, we performed immunofluorescent staining for Iba1, a marker of microglia (Imai et al., 1996; Fig. 11A-D). We focused on the hippocampus because flow cytometry had indicated an increased proportion of microglia there. We quantified the number of Iba1-positive microglia in CA1 hippocampus and found a significant increase in the number of these cells in CtcfCKO mice (Table 4; $t$ test, $t_{(298)}=5.478,{ }^{* * *} p<0.0001$ ). Compared with control microglia (Fig. 11E), we observed that microglia from Ctcf CKO mouse hippocampus had a highly bristled appearance (Fig. 11F) and uniquely demonstrated amoeboid morphology (Fig. 11G) and rod-like morphology (Fig. 11H). We evaluated microglia morphology in Ctcf CKO mice by Sholl analysis (Fig. $11 I-K$, Table $4 ; n=6$ mice/genotype, 25 microglia per mouse), which confirmed both our observation of rod-like morphology by identifying increased maximum branch length (Table 4 ; $t$ test, $\left.t_{(298)}=2.376,{ }^{\star} p=0.0181\right)$ and our observation of amoeboid morphology by identifying enlarged soma area (Table $4 ; t$ test, $\left.t_{(298)}=4.362,{ }^{* * *} p<0.0001\right)$. The bristled appearance of Ctcf CKO microglia was reflected by increased branch endpoint number (Table 4 ; $t$ test, $t_{(298)}=2.781,{ }^{* *} p=0.0058$ ) and an overall increase in the number of process intersections per Sholl radius from CtcfCKO microglia (Fig. $11 \mathrm{~K}$; rmANOVA, genotype effect, $\left.F_{(1,298)}=4.549,{ }^{\star} p=0.0338\right)$. Therefore, we found that microglia, the main mediators of innate immunity in the brain, are
Table 4. Summary of Sholl analysis of hippocampal microglia from Ctcf CKO mice and controls

\begin{tabular}{|c|c|c|c|c|c|}
\hline Measure & $\begin{array}{l}\text { Control } \\
\text { (mean } \pm \text { SEM) }\end{array}$ & $\begin{array}{l}\text { CtcfCKO } \\
\text { (mean } \pm \text { SEM) }\end{array}$ & $\begin{array}{l}t \text {-statistic } \\
\text { (df }=298)\end{array}$ & $p$-value & Significance \\
\hline Process maximum & $8.22 \pm 0.21$ & $8.37 \pm 0.22$ & 0.5008 & 0.6169 & NS \\
\hline Critical radius $(\mu \mathrm{m})$ & $15.7 \pm 0.51$ & $16.5 \pm 0.66$ & 1.001 & 0.3178 & NS \\
\hline $\begin{array}{l}\text { Number of primary } \\
\text { branches }\end{array}$ & $6.27 \pm 0.19$ & $6.63 \pm 0.18$ & 1.391 & 0.1652 & NS \\
\hline $\begin{array}{c}\text { Maximum branch } \\
\text { length }(\mu \mathrm{m})\end{array}$ & $35.5 \pm 0.77$ & $38.7 \pm 1.08$ & 2.376 & 0.0181 & * \\
\hline Branch endpoints & $34.3 \pm 1.14$ & $39.3 \pm 1.38$ & 2.781 & 0.0058 & $* *$ \\
\hline Soma area $\left(\mu \mathrm{m}^{2}\right)$ & $37.0 \pm 1.08$ & $50.1 \pm 2.79$ & 4.362 & $<0.0001$ & $* * * *$ \\
\hline $\begin{array}{l}\text { Iba1-positive cells } \\
\text { per } 63 \times \text { field }\end{array}$ & $2.65 \pm 0.08$ & $4.30 \pm 0.24$ & 5.478 & $<0.0001$ & $* * * *$ \\
\hline
\end{tabular}

The first column lists the Sholl measurement evaluated and the units of the measurement in parentheses, where applicable. The second and third columns list the mean \pm SEM for each measurement from control and Ctcf CKO mice, respectively ( $n=6 /$ genotype). The fourth column lists the $t$ statistic for each measurement using 298 degrees of freedom (df). The fifth column lists the corresponding $p$-value for Student's $t$ test. The last column indicates the degree of statistical significance. Microglia from Ctcf CKO mice had longer maximum branch length ( $t$ test: $t_{(298)}=$ $2.376,{ }^{*} p=0.0181$, more branch endpoints ( $t$ test: $t_{(298)}=2.781$, $\left.{ }^{* *} p=0.0058\right)$, and larger soma size ( $t$ test: $\left.t_{(298)}=4.362,{ }^{* * * *} p<0.0001\right)$ compared with controls. Microglia were also more numerous in Ctcf CKO mouse hippocampus as measured by the number of lba1-positive cells per $63 \times$ field of view ( $t$ test: $t_{(298)}=5.478$, ${ }^{* * * *} p<0.0001$ ). Hippocampal microglia were similar between genotypes with regard to process maximum (the maximum number of intersections per cell), the critical radius (distance from the soma where the process maximum occurred), and the number of primary branches.

NS, Not significant.

${ }^{*} p<0.05$, ${ }^{* *} p<0.01$ ， ${ }^{* * * *} p<0.0001$. 

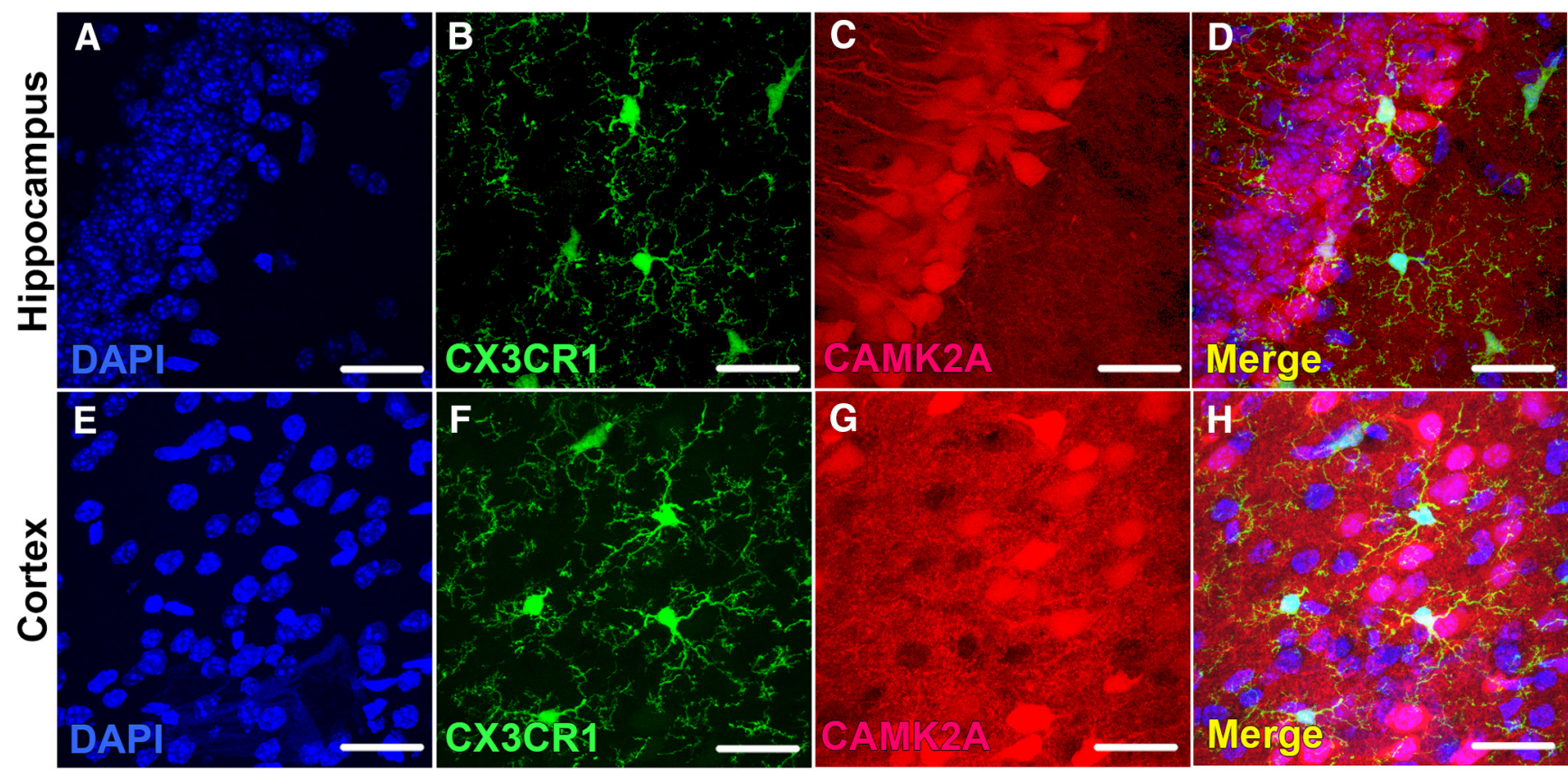

Figure 12. Microglia do not express Camk2a-Cre. The hippocampus and cortex of CX3cr1-EGFP; tdTomato; Camk2a-Cre ${ }^{+}$mice were imaged by confocal microscopy ( $n=10 \mathrm{images/brain} \mathrm{region}$ collected from 3 mice). $\boldsymbol{A}, \boldsymbol{E}$, DAPI labels cell nuclei. $\boldsymbol{B}, \boldsymbol{F}$, EGFP expressed under the control of the $(X 3 \mathrm{cr} 1$ promoter labels microglia. $\boldsymbol{C}, \boldsymbol{G}$, Red fluorescent tdTomato expressed under the control of Camk2a-Cre labels excitatory glutamatergic neurons. $\mathbf{D}, \boldsymbol{H}$, Merged images for each tissue are shown. Note the lack of overlap between the EGFP and tdTomato channels, indicating that Camk2a is not expressed in microglia. Scale bar, $25 \mu \mathrm{m}$.

increased in number and have abnormal morphology in the hippocampus of $C t c f$ CKO mice.

We sought to determine whether microglia express Camk2aCre, which would lead to microglial CTCF deficiency in CtcfCKO mice. We generated Cx3cr1-EGFP; tdTomato;Camk2a-Cre mice, which produce EGFP in microglia and red fluorescent tdTomato protein in Camk2a-Cre-expressing cells. We used confocal microscopy to collect images from CA1 hippocampus (Fig. 12A-D) and cerebral cortex (Fig. 12E-H) of Cx3crl-EGFP; tdTomato; Camk2a-Cre mice ( $n=10$ images obtained from a total of 3 mice). Neither EGFP-positive microglia from hippocampus (Fig. $12 \mathrm{D} ; n=87$ microglia) nor cerebral cortex (Fig. $12 \mathrm{H} ; n=74$ microglia) contained red fluorescent tdTomato protein, leading us to conclude that microglia do not express Camk2a in these brain regions.

Inflammation stimulates microglia to shift from a surveillance state to an activated, neurotoxic phenotype characterized by expression of the cell surface marker CD68 (Hanisch and Kettenmann, 2007; Hoogland et al., 2015). We used immunostaining to assess the amount of CD68 present in Iba1-positive microglia from the hippocampus of $\mathrm{Ctcf} \mathrm{CKO}$ mice compared with controls (Fig. 13; $n=4$ animals/genotype, $10-17$ images/animal). CD68positive microglia were rare in controls (Fig. 13A-D), but were identified frequently in images from CtcfCKO mouse hippocampus (Fig. $13 E-H$ ). We determined that the area of Iba1-positive microglia staining positive for $\mathrm{CD} 68$ was significantly greater in Ctcf CKO mouse hippocampus compared with controls (Fig. 13I; Mann-Whitney $U=345.5, n=48$ Ctcf CKO images, $n=40$ control images, ${ }^{* * * *} p<0.0001$ ), indicating increased microglial activation in Ctcf CKO hippocampus.

\section{Discussion}

Here, we describe the effects of depleting Ctcf postnatally in Camk2a-Cre expressing neurons. In contrast to Ctcf $\mathrm{KO}$ in the embryonic CNS, which is rapidly lethal (Watson et al., 2014;
Hirayama et al., 2012), we found that mice with postnatal Ctcf KO in excitatory forebrain glutamatergic neurons were viable. Ctcf CKO mice gradually developed a behavioral phenotype characterized by deficits in balance and fine motor coordination, profoundly impaired spatial learning/memory, and reduced sociability. These findings demonstrate that postnatal CTCF depletion causes a neurobehavioral phenotype independent of its effects on neural development and suggest that the phenotype of humans with CTCF haploinsufficency (Gregor et al., 2013) may be due in part to impairment of brain function caused by ongoing CTCF deficiency. CTCF interacts with methyl-CpG-binding protein 2 (MeCP2), which is encoded by MECP2, the gene mutated in the neurodevelopmental disorder Rett syndrome (Kernohan et al., 2010). A previous report described late life reversal of the neurologic phenotype of the Mecp2 KO mouse model of Rett syndrome by reexpressing wild-type Mecp2 (Guy et al., 2007). Whether the neurobehavioral phenotype of Ctcf CKO mice could be similarly improved by reconstituting CTCF sufficiency later in life is an important question to be answered.

We identified upregulation of inflammation-related genes, including known microglia genes, in CtcfCKO mouse hippocampus by performing microarray-based gene expression analysis on mRNA from whole hippocampal tissue and on mRNA specifically from Camk2a-Cre expressing hippocampal neurons lacking Ctcf, which we collected using the RiboTag ribosome affinity purification technique (Sanz et al., 2009). This unique approach allowed us to parse out the source of gene expression changes that we observed in $C t c f$ CKO hippocampus. For example, upregulation of Tlr2, Ptgs2, Ccl2, Ccl3, Ccl9, Cd14, Cd52, and Cd83 was observed in mRNA derived from whole CtcfCKO hippocampus, but not in mRNA isolated from Camk2a-Cre-expressing hippocampal neurons lacking Ctcf. This indicates that these genes are overexpressed in a non-neuronal component of the CtcfCKO hippocampus. The products of $C d 14, C d 52, C d 83$, and Tlr2 are 

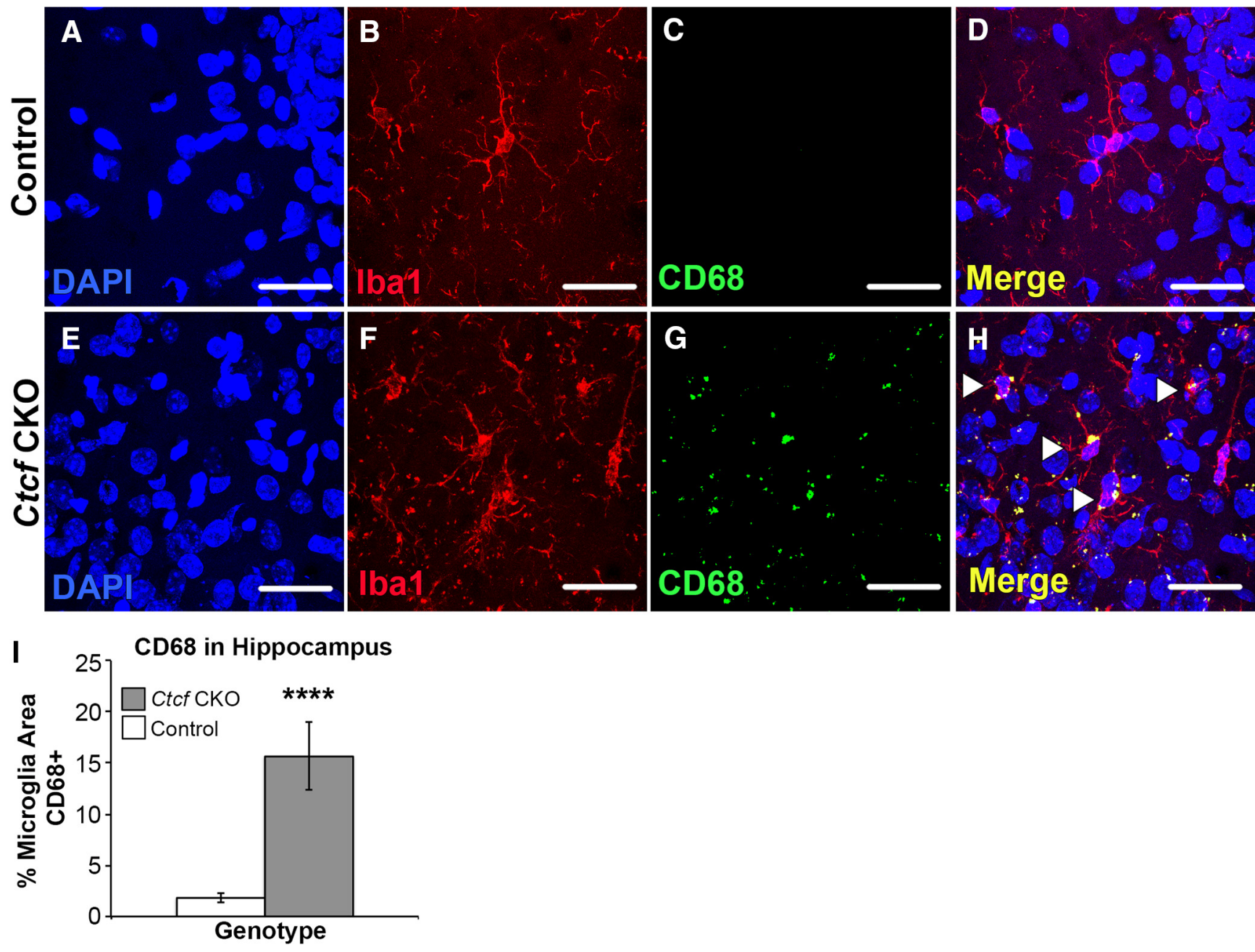

Figure 13. Hippocampal microglia in CtcfCK0 mice are positive for CD68, a marker of microglial activation. Tissue sections from CA1 hippocampus of control $(\boldsymbol{A}-\boldsymbol{D})$ and $(t \in f C K 0$ mice $(\boldsymbol{E}-\boldsymbol{H})$ were labeled with the nuclear stain $\operatorname{DAPI}(\boldsymbol{A}, \boldsymbol{E})$ and antibodies against microglial marker lba1 $(\boldsymbol{B}, \boldsymbol{F})$ and activated microglial marker $\mathrm{CD68}(\boldsymbol{C})$ and $(\boldsymbol{G})$. CD68-positive microglia are rare in controls (D), but they are common in $(t c f C K O$ mice $(\boldsymbol{H}$, arrowheads). The area of Iba1-positive microglia staining positive for CD68 was significantly greater in $C t c f C K 0$ mouse hippocampus compared with controls $\left(I ; n=48\right.$ CtcfCKO images, $n=40$ control images, Mann-Whitney $\left.U=345.5,{ }^{* * *} p<0.0001\right)$. Graph shows means \pm SEM. Scale bar, $25 \mu \mathrm{m}$.

expressed on the surface of microglia (Fujimoto and Tedder, 2006; Becher et al., 1996; Chatterjee et al., 2014; Olson and Miller, 2004; Lehnardt, 2010). Active microglia release proinflammatory prostaglandins synthesized by cyclooxygenase-2 (COX2), the product of Ptgs2 (Minghetti, 2004). Microglia also release the products of $\mathrm{Ccl} 2, \mathrm{Ccl} 3$, and $\mathrm{Ccl}$ 9: the chemokines CCL2/MCP-1 (Kim et al., 2015), CCL3 (Kataoka et al., 2009), and CCL9 (Aravalli et al., 2005), respectively. These observations prompted us to evaluate microglia in Ctcf CKO hippocampus, which were increased in number. We identified microglia with rod-like morphology, a distinct microglia phenotype found in the setting of nerve injury due to trauma and neurodegenerative disease (Tam and $\mathrm{Ma}, 2014)$. In addition, we identified microglia with amoeboid morphology, the characteristic shape of active, phagocytic microglia (Davis et al., 1994). Overall, these data point to microglia dysfunction in the setting of neuronal CTCF loss.

We identified upregulation of unique genes in mRNA obtained from Camk2a-Cre expressing neurons lacking Ctcf, but not whole $C t c f C K O$ hippocampus, including $C c l 17$. We interpret this as evidence that $C c l 17$ is overexpressed specifically in Camk2aCre-expressing hippocampal neurons lacking Ctcf, and that its twofold upregulation in these neurons is obscured in measurements of whole Ctcf CKO hippocampus gene expression. Ccl17 encodes C-C motif chemokine ligand 17 (TARC), a neuronally expressed secreted chemokine (Cheng et al., 2008) that activates C-C motif chemokine receptor 4 (CCR4) on microglia (Flynn et al., 2003). CCR4 activation promotes an M2 phenotype in macrophages/microglia that suppresses immune overactivation (Gordon, 2003). However, serum levels of CCL17 are elevated in individuals with ASD (Al-Ayadhi and Mostafa, 2013) and Alzheimer's disease (AD) (Neitzert et al., 2015) compared with healthy controls, suggesting that elevated CCL17 signaling may be pathologic. Along these lines, mouse models of $\mathrm{AD}$ deficient for $\mathrm{Ccl17}$ are protected from amyloid $\beta$ deposition, neuronal loss, and cognitive decline (Neitzert et al., 2013). Although the precise role of CCL17 is unclear in CtcfCKO mice, chemokines are broadly seen as signaling molecules capable of regulating neuron-microglia interactions (Miller et al., 2008). We interpret the upregulation and enrichment of chemokine signaling pathway genes in Camk2a-Cre-expressing hippocampal neurons lacking Ctcf, and the simultaneous upregulation and enrichment of inflammationrelated genes in the whole Ctcf CKO hippocampus, as indicative of crosstalk between neurons and microglia.

One explanation for both the upregulation of chemokine signaling pathway genes and the increase in microglia that we observed in Ctcf CKO mouse hippocampus is suggested by our 
observation of decreased dendritic spine density in this brain region. Microglia are capable of removing spines in adult animals in a process called synaptic stripping (Kettenmann et al., 2013) and chemokines are thought to serve as the major microglial attractants in this process (Trapp et al., 2007). Synaptic stripping occurs in the setting of nerve injury in both the PNS (Moran and Graeber, 2004) and CNS (Trapp et al., 2007). Injury triggers microglia to proliferate and migrate to the injury site, where they remove dendritic spines from injured neurons (Kettenmann et al., 2013), leading to dowregulation of synaptic proteins, including PSD-95 (Moran and Graeber, 2004), We did not observe nerve injury directly in Ctcf $\mathrm{CKO}$ mice, but Ctcf CKO;RiboTag neurons upregulated Nefh, which encodes neurofilament heavy polypeptide, a marker of nerve injury (Gresle et al., 2008). We speculate that microglial synaptic stripping is activated in Ctcf $\mathrm{CKO}$ mice by upregulation of chemokine signaling in Ctcf $\mathrm{KO}$ neurons, by CTCF-deficiency-induced nerve injury, or both.

Dendritic spines provide the structural basis for synaptic plasticity (Holtmaat and Svoboda, 2009), a phenomenon crucial to learning and memory (Gipson and Olive, 2017). In addition to synaptic stripping, microglia modify synaptic plasticity via direct contacts with neurons (Rogers et al., 2011; Schafer et al., 2012) and through the indirect release of growth factors including brain-derived neurotrophic factor (Coull et al., 2005) and cytokines including tumor-necrosis factor $\alpha$ (Pascual et al., 2012). Microglia also modify plasticity-related animal behavior. For example, obsessive-compulsive behavior in Hoxb8-null mice is relieved by bone marrow transplantation, which replaces mutant microglia with wild-type microglia (Chen et al., 2010). Overall, the connection between microglia and brain plasticity (Kettenmann et al., 2013), coupled with our observations of abnormal microglia in CtcfCKO hippocampus, suggest to us that microglial dysfunction contributes to the abnormalities of dendritic spines and behavior that we identified in these animals.

While this manuscript was in preparation, a description of another line of Ctcf;Camk2a-Cre CKO mice was published (Sams et al., 2016). These mice also displayed deficits in hippocampaldependent spatial learning, fear conditioning, and social recognition and had decreased dendritic spine density in CA1 hippocampus. Additional testing by the investigators identified abnormal long-term potentiation and abnormal stimulus-evoked transcription of activity-dependent $B d n f$ exon IV (Sams et al., 2016). The line of Ctcf CKO mice that we describe here confirms that deficiency of Ctcfin $C a m k 2 a$-Cre expressing neurons leads to severe deficits in spatial learning/memory, impairment in fine motor coordination, subtle alterations in social behavior, and decreased dendritic spine number. In addition, we uniquely identified upregulation of inflammation-related genes in Ctcf CKO mice and demonstrated morphological abnormalities of their microglia. Further studies will determine whether microglia are detrimental in the setting of CTCF deficiency and if approaches that modify the inflammatory state of these animals are capable of mitigating the effects of CTCF loss.

\section{References}

Al-Ayadhi LY, Mostafa GA (2013) Elevated serum levels of macrophagederived chemokine and thymus and activation-regulated chemokine in autistic children. J Neuroinflammation 10:72. CrossRef Medline

Ali H, Ahamed J, Hernandez-Munain C, Baron JL, Krangel MS, Patel DD (2000) Chemokine production by $G$ protein-coupled receptor activation in a human mast cell line: roles of extracellular signal-regulated kinase and NFAT. J Immunol 165:7215-7223. CrossRef Medline

Alvarez VA, Sabatini BL (2007) Anatomical and physiological plasticity of dendritic spines. Annu Rev Neurosci 30:79-97. CrossRef Medline
Aravalli RN, Hu S, Rowen TN, Palmquist JM, Lokensgard JR (2005) Cutting edge: TLR2-mediated proinflammatory cytokine and chemokine production by microglial cells in response to herpes simplex virus. J Immunol 175:4189-4193. CrossRef Medline

Becher B, Fedorowicz V, Antel JP (1996) Regulation of CD14 expression on human adult central nervous system-derived microglia. J Neurosci Res 45:375-381. CrossRef Medline

Cabanlit M, Wills S, Goines P, Ashwood P, Van de Water J (2007) Brainspecific autoantibodies in the plasma of subjects with autistic spectrum disorder. Ann N Y Acad Sci 1107:92-103. CrossRef Medline

Chatterjee D, Addya S, Khan RS, Kenyon LC, Choe A, Cohrs RJ, Shindler KS, Sarma JD (2014) Mouse hepatitis virus infection upregulates genes involved in innate immune responses. PLoS One 9:e111351. CrossRef Medline

Chen EY, Tan CM, Kou Y, Duan Q, Wang Z, Meirelles GV, Clark NR, Ma'ayan A (2013) Enrichr: interactive and collaborative HTML5 gene list enrichment analysis tool. BMC Bioinformatics 14:128. CrossRef Medline

Chen SK, Tvrdik P, Peden E, Cho S, Wu S, Spangrude G, Capecchi MR (2010) Hematopoietic origin of pathological grooming in Hoxb8 mutant mice. Cell 141:775-785. CrossRef Medline

Cheng H, Isoda F, Belsham DD, Mobbs CV (2008) Inhibition of agoutirelated peptide expression by glucose in a clonal hypothalamic neuronal cell line is mediated by glycolysis, not oxidative phosphorylation. Endocrinology 149:703-710. CrossRef Medline

Coull JA, Beggs S, Boudreau D, Boivin D, Tsuda M, Inoue K, Gravel C, Salter MW, De Koninck Y (2005) BDNF from microglia causes the shift in neuronal anion gradient underlying neuropathic pain. Nature 438:10171021. CrossRef Medline

Danscher G, Zimmer J (1978) An improved timm sulphide silver method for light and electron microscopic localization of heavy metals in biological tissues. Histochemistry 55:27-40. CrossRef Medline

Davis EJ, Foster TD, Thomas WE (1994) Cellular forms and functions of brain microglia. Brain Res Bull 34:73-78. CrossRef Medline

Dixon JR, Selvaraj S, Yue F, Kim A, Li Y, Shen Y, Hu M, Liu JS, Ren B (2012) Topological domains in mammalian genomes identified by analysis of chromatin interactions. Nature 485:376-380. CrossRef Medline

Dougherty JD, Maloney SE, Wozniak DF, Rieger MA, Sonnenblick L, Coppola G, Mahieu NG, Zhang J, Cai J, Patti GJ, Abrahams BS, Geschwind DH, Heintz N (2013) The disruption of Celf6, a gene identified by translational profiling of serotonergic neurons, results in autism-related behaviors. J Neurosci 33:2732-2753. CrossRef Medline

Erbayat-Altay E, Zeng LH, Xu L, Gutmann DH, Wong M (2007) The natural history and treatment of epilepsy in a murine model of tuberous sclerosis. Epilepsia 48:1470-1476. CrossRef Medline

Estes ML, McAllister AK (2015) Immune mediators in the brain and peripheral tissues in autism spectrum disorder. Nat Rev Neurosci 16:469486. CrossRef Medline

Feng G, Mellor RH, Bernstein M, Keller-Peck C, Nguyen QT, Wallace M, Nerbonne JM, Lichtman JW, Sanes JR (2000) Imaging neuronal subsets in transgenic mice expressing multiple spectral variants of GFP. Neuron 28:41-51. CrossRef Medline

Ferreira TA, Blackman AV, Oyrer J, Jayabal S, Chung AJ, Watt AJ, Sjöström PJ, van Meyel DJ (2014) Neuronal morphometry directly from bitmap images. Nat Methods 11:982-984. CrossRef Medline

Flynn G, Maru S, Loughlin J, Romero IA, Male D (2003) Regulation of chemokine receptor expression in human microglia and astrocytes. J Neuroimmunol 136:84-93. CrossRef Medline

Fujimoto Y, Tedder TF (2006) CD83: a regulatory molecule of the immune system with great potential for therapeutic application. J Med Dent Sci 53:85-91. Medline

Galatro TF, Vainchtein ID, Brouwer N, Boddeke EWGM, Eggen BJL (2017) Isolation of microglia and immune infiltrates from mouse and primate central nervous system. In: Inflammation (Clausen BE, Laman JD, eds), pp 333-342. New York: Springer.

Gilbert TH, Hannesson DK, Corcoran ME (2000) Hippocampal kindled seizures impair spatial cognition in the Morris water maze. Epilepsy Res 38:115-125. CrossRef Medline

Gipson CD, Olive MF (2017) Structural and functional plasticity of dendritic spines-root or result of behavior? Genes Brain Behav 16:101-117. CrossRef Medline

Golan-Mashiach M, Grunspan M, Emmanuel R, Gibbs-Bar L, Dikstein R, Shapiro E (2012) Identification of CTCF as a master regulator of the clus- 
tered protocadherin genes. Nucleic Acids Res 40:3378-3391. CrossRef Medline

Gordon S (2003) Alternative activation of macrophages. Nat Rev Immunol 3:23-35. CrossRef Medline

Gregor A, Oti M, Kouwenhoven EN, Hoyer J, Sticht H, Ekici AB, Kjaergaard S, Rauch A, Stunnenberg HG, Uebe S, Vasileiou G, Reis A, Zhou H, Zweier C (2013) De novo mutations in the genome organizer CTCF cause intellectual disability. Am J Hum Genet 93:124-131. CrossRef Medline

Gresle MM, Shaw G, Jarrott B, Alexandrou EN, Friedhuber A, Kilpatrick TJ, Butzkueven H (2008) Validation of a novel biomarker for acute axonal injury in experimental autoimmune encephalomyelitis. J Neurosci Res 86:3548-3555. CrossRef Medline

Guo D, Zeng L, Brody DL, Wong M (2013) Rapamycin attenuates the development of posttraumatic epilepsy in a mouse model of traumatic brain injury. PLoS One 8:e64078. CrossRef Medline

Guy J, Gan J, Selfridge J, Cobb S, Bird A (2007) Reversal of neurological defects in a mouse model of Rett syndrome. Science 315:1143-1147. CrossRef Medline

Guyenet SJ, Furrer SA, Damian VM, Baughan TD, La Spada AR, Garden GA (2010) A simple composite phenotype scoring system for evaluating mouse models of cerebellar ataxia. J Vis Exp 39: pii: 1787. CrossRef Medline

Hanisch UK, Kettenmann H (2007) Microglia: active sensor and versatile effector cells in the normal and pathologic brain. Nat Neurosci 10:13871394. CrossRef Medline

Hayward JH, Lee SJ (2014) A decade of research on TLR2 discovering its pivotal role in glial activation and neuroinflammation in neurodegenerative diseases. Exp Neurobiol 23:138-147. CrossRef Medline

Heath H, Ribeiro de Almeida C, Sleutels F, Dingjan G, van de Nobelen S, Jonkers I, Ling KW, Gribnau J, Renkawitz R, Grosveld F, Hendriks RW, Galjart N (2008) CTCF regulates cell cycle progression of $\alpha \beta$ T cells in the thymus. EMBO J 27:2839-2850. CrossRef Medline

Henry FE, Sugino K, Tozer A, Branco T, Sternson SM (2015) Cell typespecific transcriptomics of hypothalamic energy-sensing neuron responses to weight-loss. eLife 4. CrossRef Medline

Hirayama T, Tarusawa E, Yoshimura Y, Galjart N, Yagi T (2012) CTCF is required for neural development and stochastic expression of clustered Pcdh genes in neurons. Cell Rep 2:345-357. CrossRef Medline

Holtmaat A, Svoboda K (2009) Experience-dependent structural synaptic plasticity in the mammalian brain. Nat Rev Neurosci 10:647-658. CrossRef Medline

Hoogland IC, Houbolt C, van Westerloo DJ, van Gool WA, van de Beek D (2015) Systemic inflammation and microglial activation: systematic review of animal experiments. J Neuroinflammation 12:114. CrossRef Medline

Huber W, et al. (2015) Orchestrating high-throughput genomic analysis with Bioconductor. Nat Methods 12:115-121. CrossRef Medline

Imai Y, Ibata I, Ito D, Ohsawa K, Kohsaka S (1996) A novel gene ibal in the major histocompatibility complex class III region encoding an EF hand protein expressed in a monocytic lineage. Biochem Biophys Res Commun 224:855-862. CrossRef Medline

Jung S, Aliberti J, Graemmel P, Sunshine MJ, Kreutzberg GW, Sher A, Littman DR (2000) Analysis of fractalkine receptor CX(3)CR1 function by targeted deletion and green fluorescent protein reporter gene insertion. Mol Cell Biol 20:4106-4114. CrossRef Medline

Kataoka A, Tozaki-Saitoh H, Koga Y, Tsuda M, Inoue K (2009) Activation of P2X7 receptors induces CCL3 production in microglial cells through transcription factor NFAT. J Neurochem 108:115-125. CrossRef Medline

Kernohan KD, Jiang Y, Tremblay DC, Bonvissuto AC, Eubanks JH, Mann MR, Bérubé NG (2010) ATRX partners with cohesin and MeCP2 and contributes to developmental silencing of imprinted genes in the brain. Dev Cell 18:191-202. CrossRef Medline

Kettenmann H, Kirchhoff F, Verkhratsky A (2013) Microglia: new roles for the synaptic stripper. Neuron 77:10-18. CrossRef Medline

Kim YS, Kim JH, Woo M, Kim TS, Sohn KM, Lee YH, Jo EK, Yuk JM (2015) Innate signaling mechanisms controlling Mycobacterium chelonae-mediated CCL2 and CCL5 expression in macrophages. J Microbiol 53:864874. CrossRef Medline

Krishnan V, Stoppel DC, Nong Y, Johnson MA, Nadler MS, Ozkaynak E, Teng BL, Nagakura I, Mohammad F, Silva MA, Peterson S, Cruz TJ, Kasper EM, Arnaout R, Anderson MP (2017) Autism gene Ube3a and seizures impair sociability by repressing VTA Cbln 1 . Nature 543:507-512. CrossRef Medline
Lanni S, Goracci M, Borrelli L, Mancano G, Chiurazzi P, Moscato U, Ferrè F, Helmer-Citterich M, Tabolacci E, Neri G (2013) Role of CTCF protein in regulating FMR1 locus transcription. PLoS Genet 9:e1003601. CrossRef Medline

Lehnardt S (2010) Innate immunity and neuroinflammation in the CNS: The role of microglia in Toll-like receptor-mediated neuronal injury. Glia 58:253-263. CrossRef Medline

Madisen L, Zwingman TA, Sunkin SM, Oh SW, Zariwala HA, Gu H, Ng LL, Palmiter RD, Hawrylycz MJ, Jones AR, Lein ES, Zeng H (2010) A robust and high-throughput Cre reporting and characterization system for the whole mouse brain. Nat Neurosci 13:133-140. CrossRef Medline

Martínez-Cerdeño V (2017) Dendrite and spine modifications in autism and related neurodevelopmental disorders in patients and animal models. Dev Neurobiol 77:393-404. CrossRef Medline

Mégarbané A, Noguier F, Stora S, Manchon L, Mircher C, Bruno R, Dorison N, Pierrat F, Rethoré MO, Trentin B, Ravel A, Morent M, Lefranc G, Piquemal D (2013) The intellectual disability of trisomy 21: differences in gene expression in a case series of patients with lower and higher IQ. Eur J Hum Genet 21:1253-1259. CrossRef Medline

Meguro-Horike M, Yasui DH, Powell W, Schroeder DI, Oshimura M, Lasalle JM, Horike S (2011) Neuron-specific impairment of inter-chromosomal pairing and transcription in a novel model of human 15q-duplication syndrome. Hum Mol Genet 20:3798-3810. CrossRef Medline

Merkenschlager M, Nora EP (2016) CTCF and cohesin in genome folding and transcriptional gene regulation. Annu Rev Genomics Hum Genet 17:17-43. CrossRef Medline

Miller RJ, Rostene W, Apartis E, Banisadr G, Biber K, Milligan ED, White FA, Zhang J (2008) Chemokine action in the nervous system. J Neurosci 28:11792-11795. CrossRef Medline

Minghetti L (2004) Cyclooxygenase-2 (COX-2) in inflammatory and degenerative brain diseases. J Neuropathol Exp Neurol 63:901-910. CrossRef Medline

Moore JM, Rabaia NA, Smith LE, Fagerlie S, Gurley K, Loukinov D, Disteche CM, Collins SJ, Kemp CJ, Lobanenkov VV, Filippova GN (2012) Loss of maternal CTCF is associated with peri-implantation lethality of Ctcf null embryos. PLoS One 7:e34915. CrossRef Medline

Moran LB, Graeber MB (2004) The facial nerve axotomy model. Brain Res Rev 44:154-178. CrossRef Medline

Morgan JT, Chana G, Pardo CA, Achim C, Semendeferi K, Buckwalter J, Courchesne E, Everall IP (2010) Microglial activation and increased microglial density observed in the dorsolateral prefrontal cortex in autism. Biol Psychiatry 68:368-376. CrossRef Medline

Morris RGM (1981) Spatial localization does not require the presence of local cues. Learn Motiv 12:239-260. CrossRef

Moy SS, Nadler JJ, Perez A, Barbaro RP, Johns JM, Magnuson TR, Piven J, Crawley JN (2004) Sociability and preference for social novelty in five inbred strains: an approach to assess autistic-like behavior in mice. Genes Brain Behav 3:287-302. CrossRef Medline

Naert A, Callaerts-Vegh Z, D'Hooge R (2011) Nocturnal hyperactivity, increased social novelty preference and delayed extinction of fear responses in post-weaning socially isolated mice. Brain Res Bull 85:354-362. CrossRef Medline

Narendra V, Rocha PP, An D, Raviram R, Skok JA, Mazzoni EO, Reinberg D (2015) CTCF establishes discrete functional chromatin domains at the Hox clusters during differentiation. Science 347:1017-1021. CrossRef Medline

Neitzert K, Albayram Ö, Göhrs R, Müller C, Karaca I, Kumar S, Cron M, Walter J, Förster I, Bilkei-Gorzo A, Maier W, Zimmer A, Alferink J (2013) CCL17 deficiency is associated with beneficial CNS immune responses and prevents cognitive decline in a mouse model of Alzheimer's disease. Brain Behav Immun 29:S21.

Neitzert K, Albayram Ö, Ambrée O, Lundt R, Karaca I, Cron M, Müller C, Förster I, Bilkei A, Gorzo A, Jessen F, Walter J, Scheu S, Maier W, Zimmer A, Alferink J (2015) CCL17 deficiency alters myeloid cell-responses and prevents cognitive decline in APP/PS1-mice. Pharmacopsychiatry 25:A82.

Norris G, Derecki N, Kipnis J (2014) Microglial Sholl analysis. Protocol Exchange. CrossRef

Olson JK, Miller SD (2004) Microglia initiate central nervous system innate and adaptive immune responses through multiple TLRs. J Immunol 173: 3916-3924. CrossRef Medline

Page DT, Kuti OJ, Sur M (2009) Computerized assessment of social approach behavior in mouse. Front Behav Neurosci 3:48. CrossRef Medline 
Park JH, Choi Y, Song MJ, Park K, Lee JJ, Kim HP (2016) Dynamic longrange chromatin interaction controls expression of IL-21 in CD4+ T cells. J Immunol 196:4378-4389. CrossRef Medline

Parkinson H, Kapushesky M, Shojatalab M, Abeygunawardena N, Coulson R, Farne A, Holloway E, Kolesnykov N, Lilja P, Lukk M, Mani R, Rayner T, Sharma A, William E, Sarkans U, Brazma A (2007) ArrayExpress: a public database of microarray experiments and gene expression profiles. Nucleic Acids Res 35:D747-D750. CrossRef Medline

Pascual O, Ben Achour S, Rostaing P, Triller A, Bessis A (2012) Microglia activation triggers astrocyte-mediated modulation of excitatory neurotransmission. Proc Natl Acad Sci U S A 109:E197-E205. CrossRef Medline

Paul CA, Beltz B, Berger-Sweeney J (2008) The Nissl stain: a stain for cell bodies in brain sections. Cold Spring Harb Protoc 2008:pdb.prot4805. CrossRef Medline

Peters JM, Tedeschi A, Schmitz J (2008) The cohesin complex and its roles in chromosome biology. Genes Dev 22:3089-3114. CrossRef Medline

Pobbe RL, Pearson BL, Blanchard DC, Blanchard RJ (2012) Oxytocin receptor and Mecp2308/Y knock-out mice exhibit altered expression of autism-related social behaviors. Physiol Behav 107:641-648. CrossRef Medline

Raj P, et al. (2016) Regulatory polymorphisms modulate the expression of HLA class II molecules and promote autoimmunity. eLife 5: pii: e12089. CrossRef Medline

Ritchie ME, Phipson B, Wu D, Hu Y, Law CW, Shi W, Smyth GK (2015) limma powers differential expression analyses for RNA-sequencing and microarray studies. Nucleic Acids Res 43:e47. CrossRef Medline

Rogers JT, Morganti JM, Bachstetter AD, Hudson CE, Peters MM, Grimmig BA, Weeber EJ, Bickford PC, Gemma C (2011) CX3CR1 deficiency leads to impairment of hippocampal cognitive function and synaptic plasticity. J Neurosci 31:16241-16250. CrossRef Medline

Sams DS, Nardone S, Getselter D, Raz D, Tal M, Rayi PR, Kaphzan H, Hakim O, Elliott E (2016) Neuronal CTCF is necessary for basal and experience-dependent gene regulation, memory formation, and genomic structure of BDNF and Arc. Cell Rep 17:2418-2430. CrossRef Medline

Sanz E, Yang L, Su T, Morris DR, McKnight GS, Amieux PS (2009) Celltype-specific isolation of ribosome-associated mRNA from complex tissues. Proc Natl Acad Sci U S A 106:13939-13944. CrossRef Medline

Schafer DP, Lehrman EK, Kautzman AG, Koyama R, Mardinly AR, Yamasaki R, Ransohoff RM, Greenberg ME, Barres BA, Stevens B (2012) Microglia sculpt postnatal neural circuits in an activity and complementdependent manner. Neuron 74:691-705. CrossRef Medline

Silverman JL, Turner SM, Barkan CL, Tolu SS, Saxena R, Hung AY, Sheng M, Crawley JN (2011) Sociability and motor functions in Shank1 mutant mice. Brain Res 1380:120-137. CrossRef Medline

Strong E, Butcher DT, Singhania R, Mervis CB, Morris CA, De Carvalho D, Weksberg R, Osborne LR (2015) Symmetrical dose-dependent DNAmethylation profiles in children with deletion or duplication of 7q11.23. Am J Hum Genet 97:216-227. CrossRef Medline

Suzuki K, Sugihara G, Ouchi Y, Nakamura K, Futatsubashi M, Takebayashi K, Yoshihara Y, Omata K, Matsumoto K, Tsuchiya KJ, Iwata Y, Tsujii M, Sugiyama T, Mori N (2013) Microglial activation in young adults with autism spectrum disorder. JAMA Psychiatry 70:49-58. CrossRef Medline
Tam WY, Ma CH (2014) Bipolar/rod-shaped microglia are proliferating microglia with distinct M1/M2 phenotypes. Sci Rep 4:7279. CrossRef Medline

Tetreault NA, Hakeem AY, Jiang S, Williams BA, Allman E, Wold BJ, Allman JM (2012) Microglia in the cerebral cortex in autism. J Autism Dev Disord 42:2569-2584. CrossRef Medline

Trapp BD, Wujek JR, Criste GA, Jalabi W, Yin X, Kidd GJ, Stohlman S, Ransohoff R (2007) Evidence for synaptic stripping by cortical microglia. Glia 55:360-368. CrossRef Medline

Tsien JZ, Chen DF, Gerber D, Tom C, Mercer EH, Anderson DJ, Mayford M, Kandel ER, Tonegawa S (1996) Subregion- and cell type-restricted gene knockout in mouse brain. Cell 87:1317-1326. CrossRef Medline

Vargas DL, Nascimbene C, Krishnan C, Zimmerman AW, Pardo CA (2005) Neuroglial activation and neuroinflammation in the brain of patients with autism. Ann Neurol 57:67-81. CrossRef Medline

Voineagu I, Wang X, Johnston P, Lowe JK, Tian Y, Horvath S, Mill J, Cantor RM, Blencowe BJ, Geschwind DH (2011) Transcriptomic analysis of autistic brain reveals convergent molecular pathology. Nature 474:380384. CrossRef Medline

Wang H, Maurano MT, Qu H, Varley KE, Gertz J, Pauli F, Lee K, Canfield T, Weaver M, Sandstrom R, Thurman RE, Kaul R, Myers RM, Stamatoyannopoulos JA (2012) Widespread plasticity in CTCF occupancy linked to DNA methylation. Genome Res 22:1680-1688. CrossRef Medline

Watson LA, Wang X, Elbert A, Kernohan KD, Galjart N, Bérubé NG (2014) Dual effect of CTCF loss on neuroprogenitor differentiation and survival. J Neurosci 34:2860-2870. CrossRef Medline

Welsh EA, Eschrich SA, Berglund AE, Fenstermacher DA (2013) Iterative rank-order normalization of gene expression microarray data. BMC Bioinformatics 14:153. CrossRef Medline

Winkles JA (2008) The TWEAK-Fn14 cytokine-receptor axis: discovery, biology and therapeutic targeting. Nat Rev Drug Discov 7:411-425. CrossRef Medline

Wozniak DF, Hartman RE, Boyle MP, Vogt SK, Brooks AR, Tenkova T, Young C, Olney JW, Muglia LJ (2004) Apoptotic neurodegeneration induced by ethanol in neonatal mice is associated with profound learning/ memory deficits in juveniles followed by progressive functional recovery in adults. Neurobiol Dis 17:403-414. CrossRef Medline

Wozniak DF, Xiao M, Xu L, Yamada KA, Ornitz DM (2007) Impaired spatial learning and defective theta burst induced LTP in mice lacking fibroblast growth factor 14. Neurobiol Dis 26:14-26. CrossRef Medline

Yuzaki M (2017) The C1q complement family of synaptic organizers: not just complementary. Curr Opin Neurobiol 45:9-15. CrossRef Medline

Zhang Y, Chen K, Sloan SA, Bennett ML, Scholze AR, O'Keeffe S, Phatnani HP, Guarnieri P, Caneda C, Ruderisch N, Deng S, Liddelow SA, Zhang C, Daneman R, Maniatis T, Barres BA, Wu JQ (2014) An RNA-sequencing transcriptome and splicing database of glia, neurons, and vascular cells of the cerebral cortex. J Neurosci 34:11929-11947. CrossRef Medline

Zuin J, Dixon JR, van der Reijden MI, Ye Z, Kolovos P, Brouwer RW, van de Corput MP, van de Werken HJ, Knoch TA, van IJcken WF, Grosveld FG, Ren B, Wendt KS (2014) Cohesin and CTCF differentially affect chromatin architecture and gene expression in human cells. Proc Natl Acad Sci U S A 111:996-1001. CrossRef Medline 